\title{
The Stoned Proteins Regulate Synaptic Vesicle Recycling in the Presynaptic Terminal
}

\author{
Tim Fergestad, Warren S. Davis, and Kendal Broadie \\ Department of Biology, University of Utah, Salt Lake City, Utah 84112
}

The Drosophila stoned locus was identified 25 years ago on the basis of stress-sensitive behavioral mutants (Grigliatti et al., 1973). The locus is dicistronic and encodes two distinct proteins, stoned A and stoned B, which are expressed specifically in presynaptic terminals at central and peripheral synapses. Several stoned mutant alleles cause embryonic lethality, suggesting that these proteins are essential for synaptic function. Physiological analyses at the stoned synapse reveal severe neurotransmission defects, including reduced and asynchronous neurotransmitter release and rapid fatigue after repetitive stimulation. At the EM level, stoned synapses show a depletion of synaptic vesicles and a concomitant increase in membranerecycling intermediates. Mutant terminals also display a specific mislocalization of the synaptic vesicle protein synaptotagmin. These results suggest that the stoned proteins are essential for the recycling of synaptic vesicle membrane and are required for the proper sorting of synaptotagmin during endocytosis.

Key words: Drosophila; neuromuscular junction; synapse; stoned; synaptotagmin; endocytosis
Recycling of synaptic vesicles (SVs) from the plasma membrane is an essential aspect of sustained neurotransmission (Ceccarelli et al., 1973; Heuser and Reese, 1973). Although a number of proteins have been characterized as playing important roles in the SV cycle (Bennett and Scheller, 1994; Sudhof, 1995; Cremona and De Camilli, 1997; Betz and Angleson, 1998), the molecular mechanisms underlying vesicle endocytosis and subsequent maturation remain poorly understood. Systematic genetic studies of neurotransmission defects in Drosophila mutants have permitted the identification and characterization of several molecules involved in SV cycling (Broadie, 1995, 1998; Wu and Bellen, 1997). One of the most informative of these mutants has been the temperaturesensitive paralytic mutant shibire, a gene that encodes dynamin, a GTPase central to the budding of vesicle membrane during endocytosis (Koenig et al., 1983; Kosaka and Ikeda, 1983; Chen et al., 1991; De Camilli et al., 1995).

The stoned locus, like shibire, was originally identified in a screen for temperature-sensitive mutations that induce paralysis in adult flies (Grigliatti et al., 1973). Independent mutations in stoned were identified as the result of additional screens for stress-sensitive behavioral mutants (Homyk and Sheppard, 1977). These alleles include two viable mutations: $\sin ^{\mathrm{C}}$, sensitive to mechanical stress, and $s t^{\text {ts }}$, sensitive to increases in temperature (Grigliatti et al., 1973; Homyk and Sheppard, 1977). Several lines of evidence suggest stoned may have a role in synaptic function. First, viable stoned mutants display abnormal electroretinogram

\footnotetext{
Received Jan. 20, 1999; revised April 20, 1999; accepted April 28, 1999.

This study was supported by National Institutes of Health (NIH) Grant GM54544-01A1, an MDA grant, a Searle Scholarship to K.B., and by NIH Developmental Biology Training Grant 5T32 HD07491 to T.F. We are particularly grateful to L. Kelly for providing stoned mutants and stoned antibodies; to $\mathrm{K}$. Zinsmaier, H. Bellen, C. Shone, and V. Budnik for providing antibodies to CSP, Syt/Syx, Syb, and Dlg, respectively; and to C. Goodman for providing fly stocks expressing myc-tagged glutamate receptors. Special thanks to C. Rodesch and J. Rohrbough for valuable comments on this manuscript and to E. Rushton and $\mathrm{K}$. Beumer for expert technical assistance.

Correspondence should be addressed to Dr. Kendal S. Broadie, Department of Biology, University of Utah, 257 South 1400 East, Salt Lake City, UT 84112. Copyright (C) 1999 Society for Neuroscience $0270-6474 / 99 / 195847-14 \$ 05.00 / 0$
}

(ERG) recordings (Kelly, 1983; Homyk and Pye, 1989), which crudely measure massed synaptic activity in the Drosophila visual system. The stoned mutant ERGs display abnormal current transients similar to that of known synaptic mutants such as rop (Harrison et al., 1994), which encodes the Drosophila homolog of Munc-18. Second, genetic analyses of stoned revealed lethal interactions with shibire as well as dunce, which encodes a cAMPspecific phosphodiesterase with a role in learning (Dudai et al., 1976; Byers et al., 1981; Petrovich et al., 1993). Both dunce and shibire have been shown to play important roles in neurotransmission at the Drosophila neuromuscular junction (NMJ) (Koenig et al., 1983; Zhong and Wu, 1991).

Recent molecular analysis of the stoned locus has revealed that it produces a dicistronic transcript encoding two separate proteins, stoned A (STNA) and stoned B (STNB) (Andrews et al., 1996). STNA is a novel protein with no homology to known proteins. STNB has a region of partial homology with AP50, a subunit of the AP2 adaptor protein complex involved in SV endocytosis (De Camilli and Takei, 1996). Although this conserved domain has $42 \%$ amino acid identity with the AP50 family as a whole (Andrews et al., 1996), STNB is severalfold larger than AP50 and is only distantly related. Furthermore, STNB is not the Drosophila AP50 homolog because the Drosophila AP50 has recently been cloned with $86 \%$ homology to the human gene and is located at 94B1-2 (Zhang and Broadie, 1999), suggesting that STNB does not act as part of the AP2 complex. STNB also has strong homology with unc-41, a gene identified in Caenorhabditis elegans on the basis of a neurological defect (uncoordinated) and believed to have a role in SV recycling (Cremona and De Camilli, 1997). In addition, the $\mathrm{N}$ terminal of the STNB protein contains four NPF motifs (Andrews et al., 1996). These sequences are bound by an Eps15 domain, found in proteins involved in endocytosis (Tebar et al., 1996; Salcini et al., 1997), and thus may regulate interactions of STNB with proteins such as Dap160 (Roos and Kelly, 1998). The presence of the NPF motifs and the homology with UNC-41 and AP50 further suggest a role for the STNB protein in synaptic function and, in combination with 
the shibire genetic interaction, reinforce the idea of a possible role for the stoned proteins in synaptic vesicle endocytosis. Consistent with such an essential function, a number of embryonic lethal alleles of stoned have been identified (Petrovich et al., 1993).

Here, we present a comprehensive investigation of the putative role of the stoned proteins in synaptic function. A recent study by Stimson et al. (1998) has shown that the STNA protein is expressed in the NMJ and suggested, on the basis of the analysis of viable stoned mutants in the Drosophila larva, that this protein plays a role in SV exocytosis. We have confirmed and extended these studies, but, in contrast to the previous conclusion, our results strongly suggest a role for the stoned proteins in SV endocytosis. We show that both STNA and STNB are expressed specifically in the presynaptic terminal of the NMJ from early stages of synaptogenesis. Moreover, we define and characterize a number of lethal stoned mutant alleles that lack either STNB or STNA/B using confocal imaging, electrophysiology, and electron microscopy in the Drosophila embryo. These mutants have severely compromised presynaptic function and display a marked decrease in SV density and an increase in membrane-recycling intermediates in the presynaptic terminal. Furthermore, we demonstrate that the stoned proteins are required for the synaptic localization of the vesicular protein synaptotagmin and, in the absence of the stoned proteins, that synaptotagmin is inappropriately degraded. On the basis of these results, we suggest that the stoned proteins play a central role in synaptic vesicle recycling and are likely to be required for the regeneration and functional maturation of synaptic vesicles.

\section{MATERIALS AND METHODS}

Fly stocks. Analyses of embryonic mutant genotypes were done in mature Drosophila embryos raised at $25^{\circ} \mathrm{C}$. Mutant genotype was determined by failure to hatch at $22 \mathrm{hr}$ after fertilization (AF) after outcrossing to the wild-type strain Oregon-R or via use of the marked balancer chromosome FM6 grainy head-LacZ. Oregon-R was used for all control measurements. The stoned deficiency $\operatorname{Df}(1) \mathrm{HM} 430$ was obtained from the Umea stock center. The EMS-induced viable allele $\operatorname{stn}^{\mathrm{C}}$ stock was kept homozygous $w \sin ^{\mathrm{C}}$. The EMS-induced embryonic lethal allele $\operatorname{stn}^{\mathrm{R} 9-10}$ was maintained as $w^{\mathrm{a}} \operatorname{stn}^{\mathrm{R} 9-10} / \mathrm{FM} 6$ grhd-LacZ (Petrovich et al., 1993). Embryonic lethal alleles $\operatorname{stn}^{13-120}$ and $\operatorname{stn}^{\mathrm{PH} 1}$, containing transposable element insertions in the STNA and STNB reading frames, respectively, were also maintained over the FM6 grhd-LacZ balancer chromosome (Andrews et al., 1996). The $\operatorname{stn}^{\mathrm{PH} 1}$ mutation was originally identified on a multiply inverted chromosome (Zusman et al., 1985) with a lethal mutation(s) not linked to stoned as determined by failure of the $s n^{+}$duplication $\mathrm{Dp}(1: \mathrm{Y}) \mathrm{mal}^{+}$to restore adult viability. Therefore, the $s_{n}{ }^{\mathrm{PH} 1}$ chromosome was recombined to rescue viability over $\operatorname{Dp}(1$ : Y)mal ${ }^{+}$. Analysis of the original PH1 allele, the original PH1 allele heterozygous with the stoned deficiency $\mathrm{Df}(1) \mathrm{HM} 430$, and the recombined PH1 allele all independently produced identical physiological and ultrastructural results.

Histology. Rabbit polyclonal anti-stoned A and anti-stoned B antibodies, described previously (Andrews et al., 1996), were used in this study. These antisera show high binding specificity to the respective stoned proteins, as demonstrated by labeling specific bands on Western blots (Andrews et al., 1996). We have confirmed this specificity with in situ staining of mutant alleles.

Immunohistological studies were done as reported previously (Broadie and Bate, 1993a). Staged embryos and mature larva were dissected dorsally to expose the ventral muscles and laid flat using a cyanoacrylate glue. Animals were then fixed for $30 \mathrm{~min}$ in $4 \%$ paraformaldehyde in PBS (0.02 $\mathrm{M}$ phosphate buffer and $0.1 \mathrm{M} \mathrm{NaCl}, \mathrm{pH}$ 7). Preparations were washed in $0.1 \%$ Triton X-100 in PBS (PBS-TX) several times over a period of $1 \mathrm{hr}$. Preparations were incubated overnight at $4^{\circ} \mathrm{C}$ with rabbit polyclonal antisera raised against each of the stoned proteins in PBS-TX at 1:2000 (STNA) and 1:500 (STNB). Anti-cysteine string protein (1: 500) (gift from K. Zinsmaier), anti-synaptotagmin (anti-Syt; 1:500) (Littleton et al., 1993), anti-SV2 (1:50) (Developmental Studies Hybridoma Bank, University of Iowa), anti-syntaxin 1A (1:500) (Schulze et al.,
1995), anti-synaptobrevin (anti-Syb; 1:1000) (Shone et al., 1993; Sweeney et al., 1995), and anti-horseradish peroxidase (anti-HRP; 1:100) (Jan and Jan, 1982) were used to label presynaptic domains. Anti-discs-large protein (anti-DLG; 1:300) (Lahey et al., 1994) and anti-myc (1:100) [clone 9E10 from Developmental Studies Hybridoma Bank, University of Iowa; used with the myc-tagged glutamate receptor (GluR) strain] (Petersen et al., 1997) antibodies were used to label the postsynaptic domains. Staining was visualized using an avidin-conjugated FITC antirabbit (Vector Laboratories, Burlingame, CA) and a rhodamineconjugated anti-mouse secondary antibody (1:500; Vector Laboratories). Fluorescent images were acquired on a Bio-Rad MRC 600 confocal microscope (Hercules, CA), and all images were presented using Adobe Photoshop 4.0 software.

For quantified experiments, mutant strains were dissected, processed, and imaged on the same coverslip as wild-type specimens to ensure all animals were processed identically. Confocal image acquisition settings were identical for all specimens examined in an experiment. Labeled bouton pixel intensities were quantified using NIH Image software and normalized to wild type. Four boutons were analyzed per junction, and several animals $(>5)$ per genotype were analyzed in an experiment $(n>20)$. All synapses examined were at muscle 12. Statistical analyses (Mann-Whitney $U$ tests) were done using Instat software (Graph Pad, San Diego, CA).

Western blot analysis. Synaptotagmin protein expression in stoned mutant embryos was assayed on Western blots using the DSYT2 antisynaptotagmin antibody (1:1000) (Littleton et al., 1993). Embryos were collected as described above, and the total protein preparation was performed using five embryos per strain, homogenizing $\left(4^{\circ} \mathrm{C}\right)$ in a Laemmli sample buffer (Bio-Rad, Hercules, CA) plus complete protease inhibitor (Boehringer Mannheim, Indianapolis, IN). Ten percent acrylamide gels were loaded with total protein consisting of five embryos per well. Gels were run using a Mini-PROTEAN II electrophoresis cell and transferred to a nitrocellulose membrane using the Mini Trans-Blot apparatus (Bio-Rad). By the use of ECL detection (Amersham, Arlington Heights, IL), Western blots were developed to be linear in the range used for densitometry (subsaturating). The density of bands was quantified using a Duo scanner and NIH Image software. Background intensity levels were subtracted, and synaptotagmin expression values for each strain were adjusted using actin levels to control for variability in total loaded protein. Each measure was repeated three times per blot to obtain average values.

Electrophysiology. Electrophysiological recordings were performed as reported previously (Broadie and Bate, 1993b). Briefly, embryos were dissected in recording saline at $22-24 \mathrm{hr} \operatorname{AF}\left(25^{\circ} \mathrm{C}\right)$. Lethal mutant animals were balanced over an FM6 grhd:lac- $Z$ labeled chromosome and selected for the homozygous mutant genotype based on $\beta$-galactosidase staining after the blind recording session. Recordings were made at $18^{\circ} \mathrm{C}$ using an Axopatch 1D amplifier and standard whole-cell patch-clamp $(-60 \mathrm{mV})$ techniques. Recordings were taken from muscle 6 in anterior abdominal segments A2-A3. Excitatory junctional currents (EJCs) were evoked by brief stimulation of the motor nerve $(1 \mathrm{msec})$ with positive current using a suction electrode. Mean EJC amplitudes in each animal were determined from 25 consecutive EJCs evoked at each frequency. Data for the cumulative current analysis were grouped into $1 \mathrm{msec}$ bins and normalized. Salines consisted of (in $\mathrm{mm}$ ): $135 \mathrm{NaCl}, 5 \mathrm{KCl}, 1.8$ $\mathrm{CaCl}_{2}, 4 \mathrm{MgCl}_{2}, 5 \mathrm{~N}$-tris(hydroxymethyl)methyl-2-aminoethanesulfonic acid (TES), and 36 sucrose, pH 7.15 (external); $120 \mathrm{KCl}, 20 \mathrm{KOH}, 0.25$ $\mathrm{CaCl}_{2}, 4 \mathrm{MgCl}_{2}, 5$ TES, 5 EGTA, 4 NaATP, and 36 sucrose, pH 7.15 (internal). Data were acquired and analyzed using pCLAMP 6.0 software (Axon Instruments).

Fatigue protocols were done immediately after basal stimulation and consisted of 25 stimuli at $10 \mathrm{~Hz}$ presented every $15 \mathrm{sec}$ over a $5 \mathrm{~min}$ period. Mean EJC amplitudes were determined from all 25 consecutive stimuli for a given time point. Calcium dependence was determined by characterizing the power relationship of basal EJC amplitudes $(1 \mathrm{~Hz}$ stimulation) at low calcium concentrations (0.1-0.4 mM) (Broadie et al., 1994). Miniature EJCs (MEJCs) were acquired from at least six animals per strain and consisted of at least 5 min of continuous recording. All MEJC recordings were done at $0.5 \mathrm{~mm}$ external calcium. Only type I MEJCs were analyzed for amplitude and frequency using Mini Analysis software 3.0 (Jaejin Software).

Electron microscopy. Late stage 17 embryos were prepared for transmission electron microscopy (TEM) using a modified version of previous procedures (Broadie et al., 1995; Prokop et al., 1996). Identification of mutant embryos in lethal strains $\left(\operatorname{stn}^{13-120}, \operatorname{stn}^{\mathrm{R} 9-10}\right.$, and $\left.s n^{\mathrm{PH} 1}\right)$ was 
facilitated by use of the balancer chromosome FM6 grhd-LacZ. To control for possible secondary mutations in $s n^{\mathrm{PH} 1}$ flies, we also crossed $s{ }^{\mathrm{PH} 1}$ to $\mathrm{Df}(1) \mathrm{HM} 430$ for further analysis. Hourly egg lays were allowed to develop at $25^{\circ} \mathrm{C}$ until animals began hatching. Unhatched embryos were manually dechorionated and injected with fixative (5\% glutaraldehyde in $0.05 \mathrm{M}$ phosphate buffer). Anterior and posterior extremities were excised and, for lethal strains, transferred to 5-bromo-4-chloro-3indolyl- $\beta$-D-galactopyranoside at $37^{\circ} \mathrm{C}$. The main portion of the embryo was transferred to $2.5 \%$ glutaraldehyde in $0.05 \mathrm{~m}$ phosphate buffer for 30-60 min. Specimens were washed three times in buffer and transferred to $1 \%$ osmium tetroxide in $\mathrm{dH}_{2} 0$ for $3 \mathrm{hr}$. Before further processing, extremities from lethal strain specimens were examined for $\beta$-galactosidase activity, and nonhomozygous mutant (blue) embryos were discarded. Specimens were washed four times in $\mathrm{dH}_{2} 0$, stained en bloc in $2 \%$ aqueous uranyl acetate for $30 \mathrm{~min}$, dehydrated in an ethanol series, passed through propylene oxide, and transferred to araldite. Ribbons of thin $(\sim 55 \mathrm{~nm})$ sections were obtained and examined on a Hitachi H-7100 TEM. Active zones that were identified in at least two consecutive sections were imaged. Morphometric analysis was performed using the public domain NIH Image software package. The radial dimension of synaptic vesicle clusters surrounding active zones was estimated for 21 wild-type t-bars, and the average of these measures (250 $\mathrm{nm}$ ) was used as the radial dimension for counting clustered vesicles and large vesicles within active zone clusters. Large vesicles (cisternae) were determined as having diameters $>60 \mathrm{~nm}$. Significance values were calculated using Mann-Whitney $U$ tests.

\section{RESULTS}

\section{The stoned proteins are expressed in} presynaptic terminals

Using antibodies specific for the stoned proteins (Andrews et al., 1996), we assayed the distribution of STNA and STNB in the nervous system. Both proteins are strikingly expressed at synaptic connections both in the CNS (data not shown) and at the NMJ (Fig. 1) in the mature embryo (20-22 hr AEL) and throughout larval development. In the third instar NMJ, both stoned proteins are highly expressed in all synaptic bouton types, including type I, II, and III boutons (Johansen et al., 1989; Jia et al., 1993) (Fig. 1). Both STNA (Fig. $1 A$ ) and STNB (Fig. $1 B$ ) proteins show precise colocalization with presynaptic markers, such as the synaptic vesicle-associated cysteine string protein (CSP), suggesting a presynaptic localization. Double-labeling experiments using antibodies against known postsynaptic proteins, such as the membrane-associated DLG (Lahey et al., 1994), show the presynaptic STNA (Fig. 1C) and STNB (Fig. 1D) proteins surrounded by a halo of the postsynaptic marker (DLG), consistent with restriction of the stoned proteins to the presynaptic region. Similar results were obtained using a different postsynaptic marker, the GluRII glutamate receptor, which also shows a halo of GluR protein expression surrounding the stoned labeling (data not shown). These results suggest that both stoned A and B are present exclusively at the presynaptic compartment where the proteins colocalize with SV pools.

\section{Stoned is required for embryonic viability and coordinated movement}

Several lethal stoned alleles have been identified, including two transposable element insertions, $\operatorname{stn}^{13-120}$ and $\operatorname{stn}^{\mathrm{PH} 1}$, that lie in the STNA and STNB reading frames, respectively, and an EMSinduced allele, $\operatorname{stn}^{\mathrm{R} 9-10}$, that has not been characterized at the molecular level (Petrovich et al., 1993). All of these lethal stoned mutants die as mature embryos after a failure to hatch from the egg case, apparently from lack of coordinated movement. This defect is not a result of alterations in gross embryonic morphology; mutant embryos show normal segmental patterning of the epidermis, muscles, and nervous system (data not shown). Thus, the mutant embryos appear morphologically normal but are impaired in the ability to move in a coordinated manner.

Wild-type and mutant embryos (22-24 hr) were labeled with each of the stoned antibodies to determine the effect of each mutation on protein expression and localization (Fig. 2). At the embryonic wild-type NMJ, STNA and STNB proteins are highly concentrated in presynaptic boutons. None of the stoned mutant alleles display detectable STNB staining in the synaptic terminal, including the viable $\operatorname{stn}^{\mathrm{C}}$ embryo (Fig. $2 B$ ) and the $\operatorname{stn}^{\mathrm{C}}$ third instar larva (data not shown). In contrast, the mutants show variable levels of STNA expression. Both the $\operatorname{stn}^{13-120}$ and $s t n^{\mathrm{R} 9-10}$ alleles have severely reduced or undetectable levels of STNA expression, whereas the $s{ }^{\mathrm{PH} 1}$ allele appears to have only moderately reduced levels of STNA (Fig. 2). The viable $\operatorname{stn}^{\mathrm{C}}$ mutant NMJ also shows strongly reduced or undetectable STNA staining at $22 \mathrm{hr} \mathrm{AF}$ (Fig. 2A); however these animals do display very weak STNA expression at the third instar NMJ (data not shown). These results suggest that a mutation in the first open reading frame of the dicistronic stoned locus (STNA) renders the second reading frame (STNB) unreadable. Thus, the $\operatorname{stn}^{\mathrm{PH} 1}$ allele primarily removes the STNB product, consistent with the transposable element insertion in the second reading frame (STNB), whereas all other alleles strongly effect the expression of both STNA and STNB.

\section{Synaptotagmin is specifically mislocalized in stoned mutants}

Using a number of immunological markers, stoned mutant NMJs appear morphologically and molecularly similar to those of wildtype, although the terminals appear slightly smaller than normal (Fig. 3). Despite this slight structural difference, the mutant NMJs display clear, punctate expression of several vesicle-associated proteins in the synaptic boutons, including CSP and Syb (Fig. 3). In addition, the expression of other synaptic markers including a neuronal membrane marker (HRP), syntaxin (Syx), and Rab3 appeared normal in the mutant terminals (data not shown). The quantified expression level and bouton localization of the synaptic proteins are similar to that of wild type.

In contrast, Syt protein appears to be strikingly mislocalized in all four stoned mutant alleles (Fig. $3 A$ ). Instead of the punctate bouton localization of Syt observed in wild type, the stoned mutants display reduced Syt expression in the boutons and the protein aberrantly dispersed throughout the presynaptic terminal (Fig. 3A). This mislocalization is not resolved with development in the viable $s{ }^{\mathrm{C}}$ allele because Syt expression remains mislocalized at the third instar NMJ (data not shown) (Stimson et al., 1998). Double-labeling assays with other presynaptic markers indicate this mislocalization is specific to Syt, because CSP, the neuronal membrane marker HRP, another SV protein (Syb), and the membrane protein Syx (data not shown) display normal patterns of expression in all mutants (Fig. 3). These results suggest that stoned mutants specifically mislocalize the SV protein Syt in the synaptic terminal and retain other synaptic proteins properly.

For all four mutant alleles, the intensity of the Syt and CSP expression in individual, double-labeled boutons was quantified using digital confocal imaging and compared with wild-type expression levels in parallel trials (Fig. 4A). All mutants show an equal and similar $\sim 40-60 \%$ loss of Syt synaptic localization, compared with the normal expression and localization of CSP. This reduction in Syt expression was significant in all four alleles, and the alleles were not significantly different from each other 

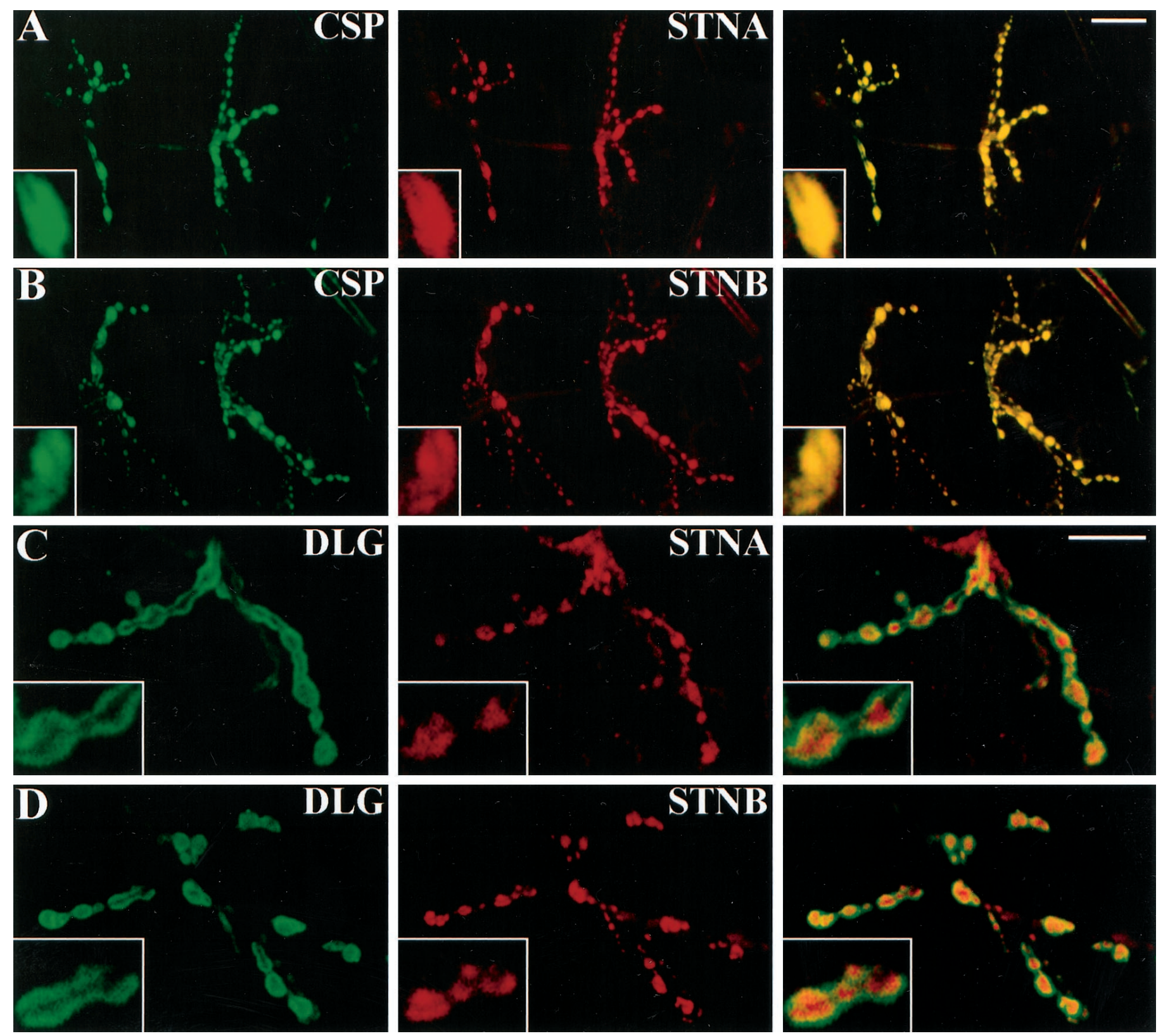

Figure 1. The stoned proteins are expressed presynaptically at synaptic terminals. $A, B$, Third instar larval NMJs double-labeled for the synaptic vesicle-associated CSP (green) and STNA $(A$, red) or STNB $(B$, red). Right, Merged images showing the colocalization of each of the stoned proteins with CSP. Insets, Boutons at higher magnification with CSP and the stoned proteins precisely colocalized. $C, D$, Larval NMJs double-labeled for the postsynaptic DLG ( green) and STNA $(C$, red $)$ or STNB $(D$, red $)$. Right, Merged images displaying the presynaptic expression of the stoned proteins (red) surrounded by a halo of the postsynaptic DLG ( green). Insets, Magnified boutons with the red stoned proteins surrounded by the green postsynaptic DLG. Scale bars: $A, B, 50 \mu \mathrm{m} ; C, D, 30 \mu \mathrm{m}$.

(Fig. 4A). Syt expression in whole embryos was analyzed to determine further the nature of the synaptic loss of Syt staining. Quantified Western blots were performed to determine Syt expression levels in the different stoned alleles (Fig. 4C). Mutants display a significant decrease in Syt levels, with protein levels in the range of $20-60 \%$ of those found in wild-type embryos (Fig. $4 B$ ). The decrease in in situ synaptic localization is consistent with the loss of Syt displayed on Western blots (compare Fig. $4 \mathrm{~A}$ with $B$ ). These findings suggest that Syt is not only mislocalized in stoned mutants but may also be subject to rapid degradation when not properly localized.

\section{Stoned mutants display severely impaired synaptic transmission}

To determine whether the striking synaptic staining pattern for the stoned proteins is consistent with a physiological function at the synapse, we assayed transmission properties with electrophysiological recordings at the embryonic NMJ. In all stoned mutant alleles, nerve stimulation produces muscle contraction, demonstrating that presynaptic depolarization evokes transmitter release and that the muscle excitation-secretion response is intact. However, evoked EJC peak amplitudes are significantly reduced below wild-type levels, typically by $30-50 \%$, for all stoned alleles 

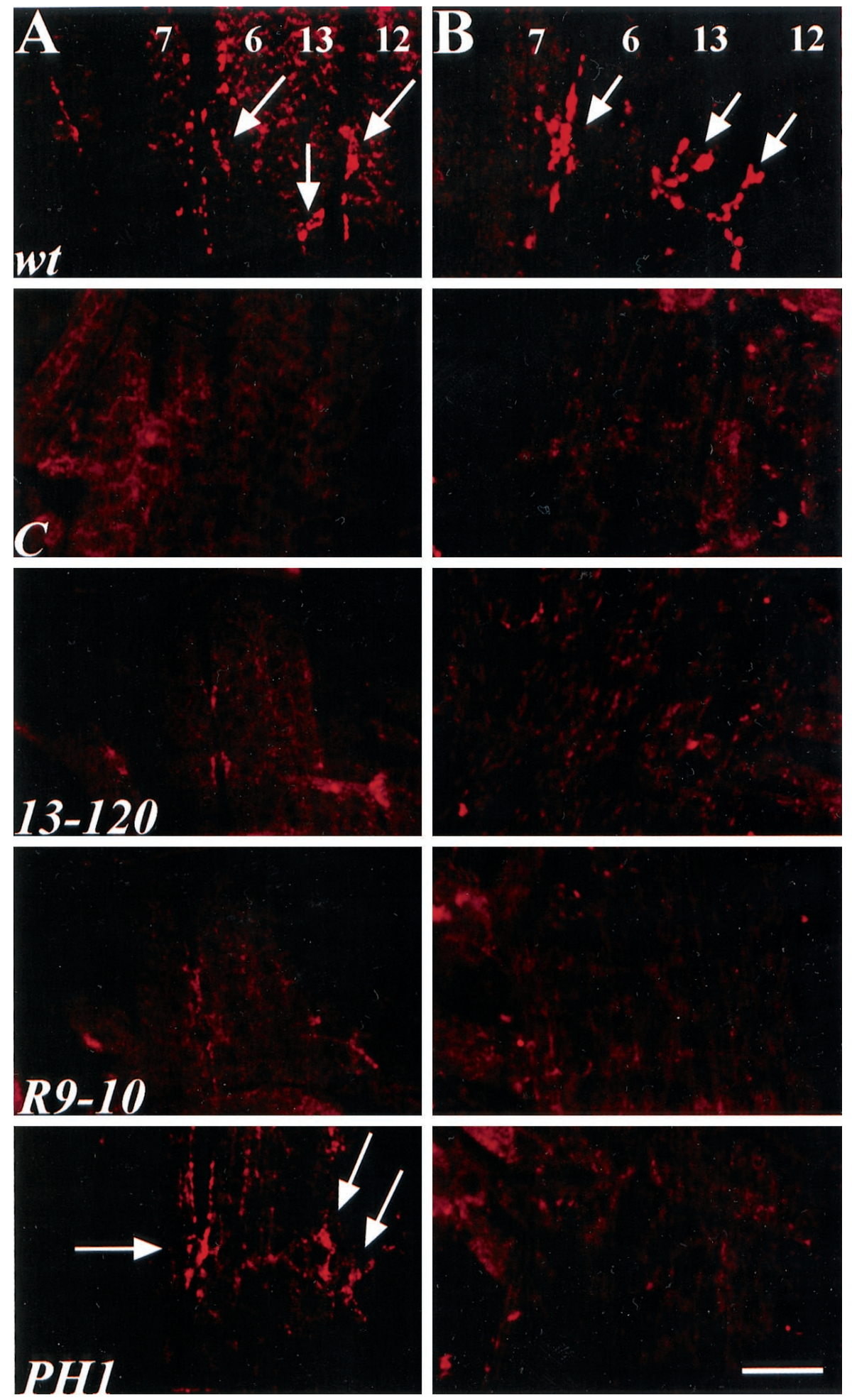

Figure 2. All stoned mutant alleles eliminate STNB expression, and most reduce or eliminate STNA expression. $A$, STNA antibody labeling of embryonic NMJ shows virtually undetectable STNA expression in $\operatorname{stn}^{\mathrm{C}}(C), \operatorname{stn}^{13-120}(13-120)$, and $\operatorname{stn}^{\mathrm{R} 9-10}(\mathrm{R} 9-10)$ alleles. The $\operatorname{stn}^{\mathrm{PH} 1}$ (PH1) allele displays near wild-type levels of STNA expression. $B$, STNB antibody labeling shows that all stoned mutant alleles lack detectable protein levels at the embryonic NMJ. $w t$, Wild type. Scale bar, $20 \mu \mathrm{m}$.
(Fig. 5A,B). Furthermore, the release of neurotransmitter at mutant synapses is markedly asynchronous (Fig. $5 A$ ). The asynchronous mutant transmission seems to result from delayed presynaptic vesicle fusion, similar to that observed for the previously identified synaptotagmin mutant (Broadie et al., 1994).

Delayed transmission was quantified by determining the delay from stimulus to peak current response (Fig. $5 C$ ), as well as the analysis of the time to half-maximal current $\left(I_{50}\right)$ for all stoned alleles (Fig. 5D). Both of these analyses found a significant in- crease in the amount of time to stimulus response, suggesting that the rate of mutant transmitter release is impaired. Asynchronous release was quantified by analyzing the number of EJC peaks per stimulus. The wild-type response to a single stimulus usually results in a single current peak, representing coordinated release from a large number of vesicles (Fig. $5 A$ ). In contrast, the stoned mutant alleles display a significant increase in the average number of peaks per stimulus (Fig. $5 A, E$ ). These data suggest that all of the stoned mutants have an impaired ability to synchronously 

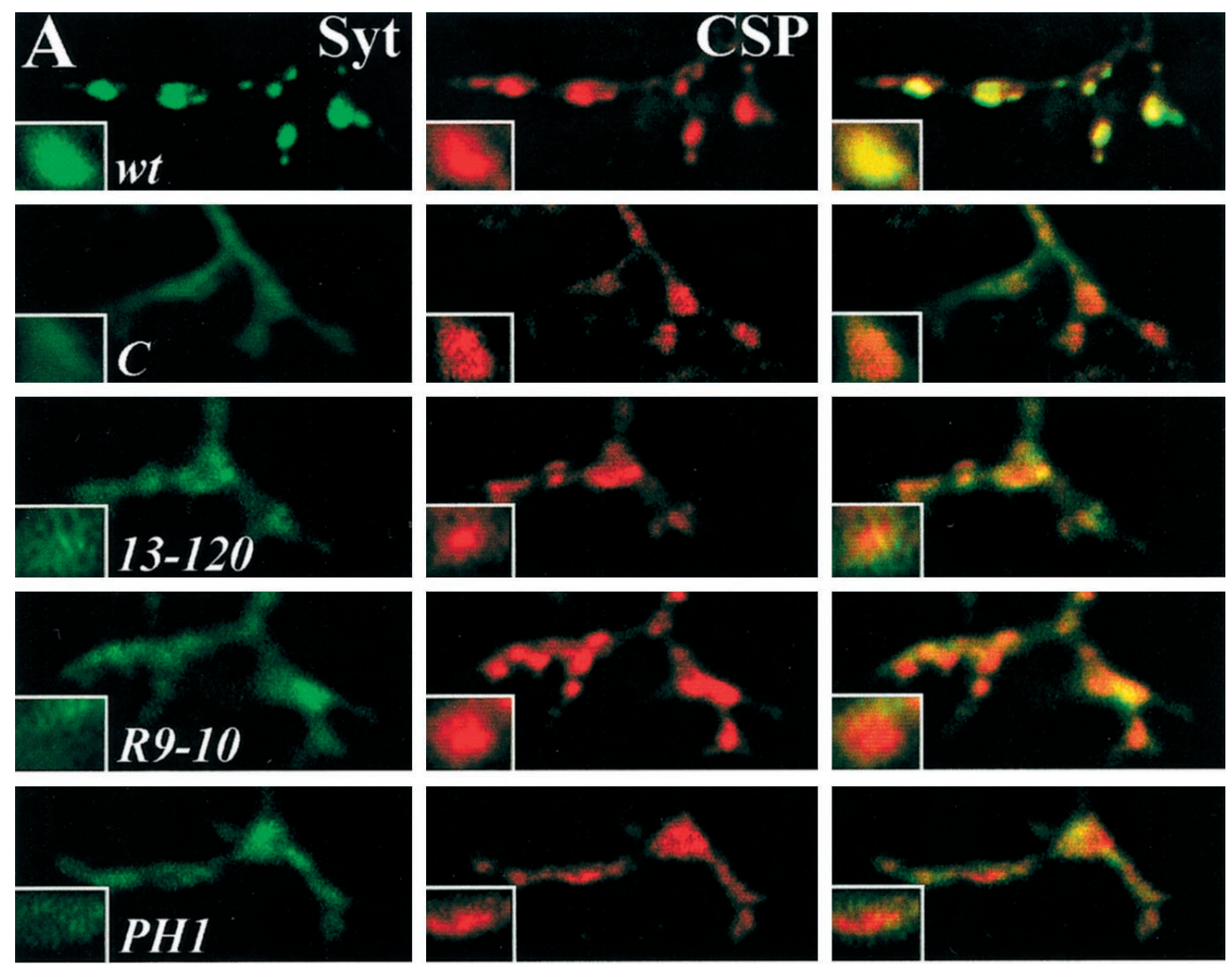

Figure 3. Synaptotagmin is reduced and mislocalized at stoned presynaptic boutons. $A$, Embryonic NMJs doublelabeled with antibodies to the SV protein Syt (green) and the SV-associated protein CSP (red). The Syt-staining pattern in wild-type embryos shows distinct punctate expression in the boutons that colocalizes with CSP expression. Mutant synapses have reduced and mislocalized Syt expression but maintain punctate CSP expression. Syt expression in mutants appears dispersed throughout the presynaptic terminal including innervating axons. $B$, Embryonic NMJs double-labeled with antibodies against the SV protein Syb (red) and a neuronal membrane marker recognized by antibodies against HRP (green). The entire nerve terminal is labeled by HRP, and wild-type synapses display strong Syb expression at the boutons. Mutant animals display properly localized Syb that has punctate expression at the boutons, substantially different from the sparse expression pattern of Syt. Scale bar, $5 \mu \mathrm{m}$.
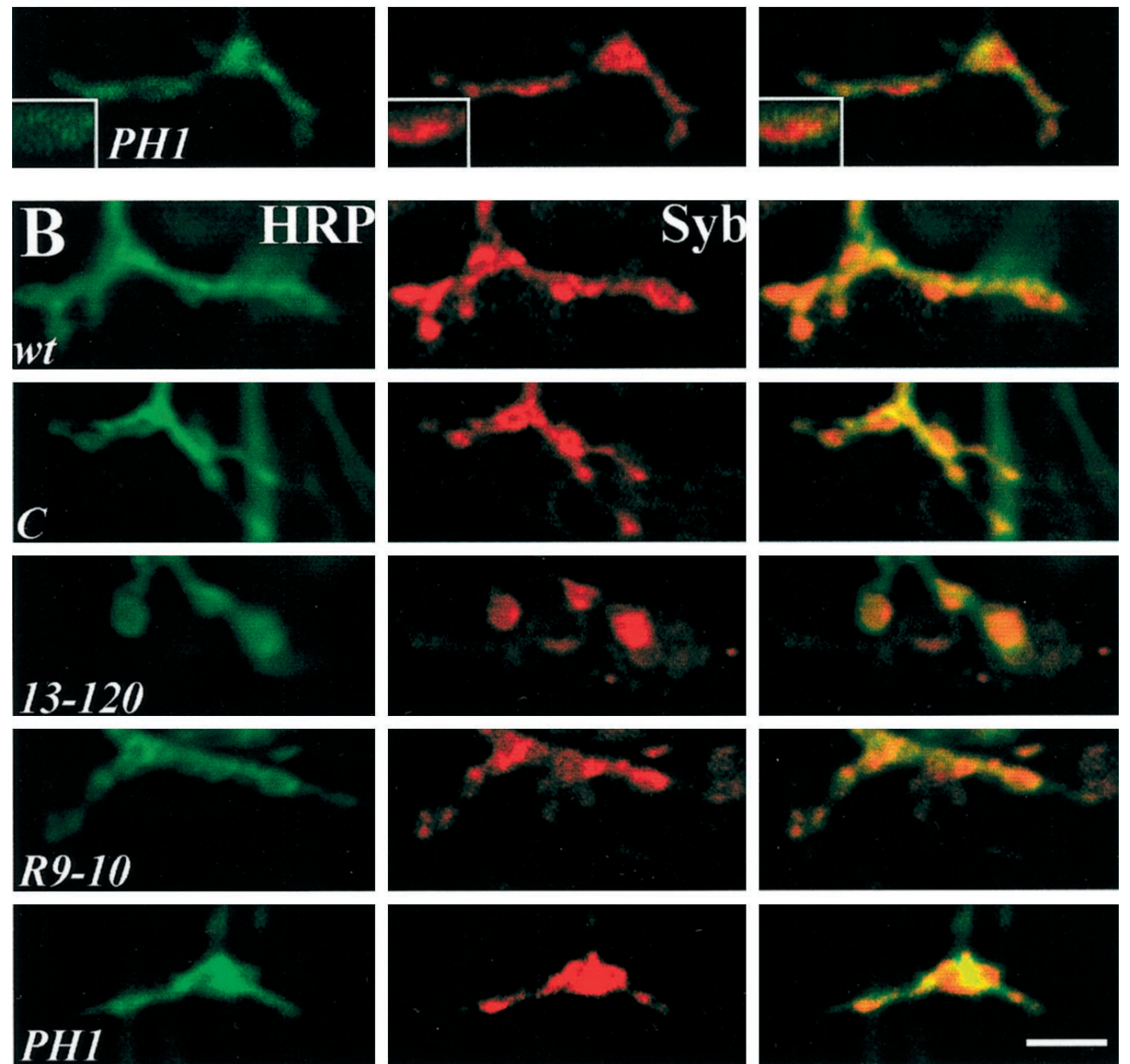

trigger calcium-mediated vesicle fusion, which results in a significant delay in peak transmission rate. To determine whether the decreased EJC amplitude is caused solely or in part by the asynchronous transmission, we measured the average area of the total synaptic current. We observed that the total synaptic current area was decreased, similar to the peak amplitude values, in all mutants compared with wild type (data not shown). Therefore, we conclude that stoned mutants display delayed fusion, asynchronous transmission, and an overall decreased level of neurotransmitter release.

As a measure of transmission fidelity, the variability in EJC peak amplitudes was compared between wild-type and mutant NMJs (Fig. $5 F$ ). Wild-type synapses display strong, high-fidelity transmission and never fail to release transmitter in response to 

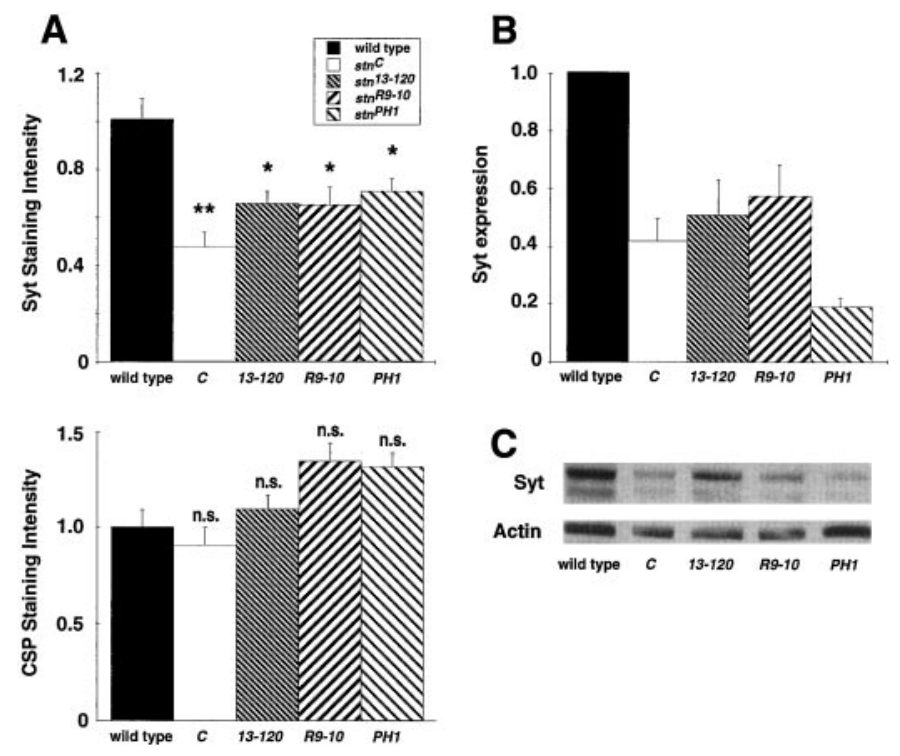

Figure 4. Synaptotagmin levels are reduced in stoned mutant embryos. $A$, Confocal images of embryonic NMJs (Fig. 3) double-labeled with antibodies to Syt and CSP were analyzed for pixel intensity. All animals were dissected and processed with wild-type animals, and images were acquired with identical settings. The amount of Syt and CSP signal intensity in single boutons was determined for all strains and normalized to that of wild type for that same experiment. All stoned mutant boutons show a significant $\sim 50 \%$ reduction in the amount of Syt (Mann-Whitney $U$ test, $p<0.001$ for all strains). In contrast, CSP levels were not significantly different from wild-type levels in any stoned allele. n.s., Not significant. $B$, $C$, Western blot analysis of stoned mutant whole embryos shows a strong reduction in Syt levels. $B$, The plot displays the average synaptotagmin intensity for the stoned mutants after actin normalization for deviations in protein loading from independent trials. All values represent the mean \pm SEM. Syt levels were significantly decreased in all stoned alleles (MannWhitney $U$ test, $p<0.001$ for all strains). $C$, A sample gel is shown. The lower band identified by the DSYT2 antibody represents a previously characterized Syt breakdown product (Littleton et al., 1993).

depolarizing stimuli over a range of stimulus frequencies (1-20 $\mathrm{Hz}$ ) in $1.8 \mathrm{~mm}\left[\mathrm{Ca}^{2+}\right.$ ] (Fig. $\left.5 A, F, G\right)$. In contrast, the viable $\operatorname{stn}^{\mathrm{C}}$ allele and lethal $\operatorname{stn}^{\mathrm{R} 9-10}$ exhibit approximately twofold greater variability than normal. The $\operatorname{stn}^{13-120}$ and $\operatorname{stn}^{\mathrm{PH} 1}$ alleles exhibit the most severely decreased transmission fidelity, with $>75 \%$ variability in EJC amplitude (Fig. $5 F$ ). This heightened transmission variability is slightly reduced at higher stimulation rates (5-20 Hz) because of induced frequency-dependent facilitation but decreases again immediately at lower stimulation frequencies (Fig. 5B,F). The severely decreased mutant transmission reliability is accompanied by complete failures to release transmitter in response to neuronal stimulation. All stoned mutants show a significant number of evoked transmission failures over the entire range of stimulation frequencies $(1-20 \mathrm{~Hz}$; Fig. $5 G)$, although the level of failure is reduced at higher stimulation frequencies. These results demonstrate a severe loss of transmission fidelity in all the stoned mutants, again similar to the previously characterized synaptotagmin mutants (Broadie et al., 1994).

The calcium dependence of transmission was assayed in the range of $0.1-1.8 \mathrm{~mm}\left[\mathrm{Ca}^{2+}\right]$ to determine whether there was any alteration in the calcium sensitivity of release in the mutant phenotype. The EJC amplitude of the mutants is significantly lower than that of wild type at all external calcium levels, but this transmission defect did not show any obvious change in calcium dependence (Fig. 5H). At low calcium levels (0.1-0.4 mм), in which EJC amplitude is linearly related to the calcium concentration when plotted in log coordinates, the slopes of the stoned mutant relationships show no significant change in the calcium dependence of transmission compared with that of wild type (Fig. $5 H$ ). These results suggest that stoned does not affect the basic calcium sensitivity of transmission.

To address whether a change in the state of the presynaptic release machinery could explain the changes in evoked transmission, we examined the frequency and amplitude of MEJCs (Fig. 6 ). The frequency of MEJCs is not significantly altered in any of the mutants, suggesting that stoned does not affect the rate of constitutive SV fusion (Fig. 6A). However, all of the stoned mutants exhibit a significant increase in the average MEJC amplitude, by as much as twofold in some alleles (Fig. 6B). The representative amplitude histogram shown for $\operatorname{stn}^{\text {R9-10 }}$ demonstrates a distribution of quantal release amplitudes (20-200 pA) similar to that of wild type, suggesting no alteration in the postsynaptic receptor field (Fig. 6C). However, a high frequency of abnormally large events $(>200 \mathrm{pA})$ was observed at mutant synapses that are rare in wild type. Similar increases in largeamplitude MEJC frequency was observed in all stoned alleles. These results suggest that constitutive vesicle fusion probability is not altered in stoned mutants but that an increased amount of transmitter may be released from a certain class of vesicles.

\section{Stoned mutant synapses exhibit severe fatigue after prolonged stimulation}

The reduced and erratic evoked transmission of stoned mutants was further increased after prolonged, repetitive stimulation at moderate or high frequencies $(5-20 \mathrm{~Hz})$. To determine the nature of this debilitation, we subjected animals to a high-frequency stimulus protocol $(10 \mathrm{~Hz})$ sustained over a 5 min period (Fig. $7 A$ ). The average EJC amplitude at wild-type NMJs decreases by an absolute amount similar to that of mutant animals ( $500 \mathrm{pA})$, suggesting that the NMJ of both genotypes is fatiguing comparably. However, the stoned mutants start with significantly impaired performance and fatigue by an average of 50-75\% during the stimulus train, whereas wild-type amplitude decreases by only $\sim 20-25 \%$ (Fig. $7 B$ ).

The decrease in mean EJC amplitude is accompanied by a large increase in transmission failure in the stoned synapses. Wild-type synapses maintain high-amplitude, high-fidelity transmission over a sustained stimulation period of $5 \mathrm{~min}$ and show no failures even at the end of the stimulus train (Fig. $7 A, B$ ). In contrast, the failure frequency of the mutant synapses is initially significant $(\sim 5-10 \%)$ and increases rapidly during sustained stimulation to a level of $25-80 \%$ at the end of the stimulus train (Fig. $7 C)$. The three alleles that more strongly affect both STNA and STNB expression $\left(s t n^{\mathrm{R} 9-10}, \operatorname{stn}^{13-120}\right.$, and $\left.\operatorname{stn}^{\mathrm{C}}\right)$ show a more marked transmission failure rate $(50-80 \%)$ than does the primarily STNB mutant $\left(\operatorname{stn}^{\mathrm{PH} 1} ; 25 \%\right)$. The striking increase in failure rate during a prolonged stimuli train suggests that repetitive stimulation results in a severe depletion of SVs in the stoned mutants.

\section{Stoned mutant synapses display decreased synaptic vesicle density and accumulate membrane-recycling intermediates}

The Drosophila embryonic NMJ is characterized by the presence of presynaptic varicosities (boutons) containing specialized, densely staining, T-shaped structures (t-bars) at the presynaptic active zones (Fig. 8) (Osborne, 1975), the putative SV fusion sites (Heuser et al., 1979; Govind et al., 1980; Probst and Ko, 1987; 
Figure 5. All four stoned mutant alleles exhibit strongly impaired presynaptic function. $A$, Neurotransmission was assayed by stimulating the embryonic nerve with a suction electrode at $1 \mathrm{~Hz}$ while recording EJCs in the voltage-clamped muscle $(-60 \mathrm{mV})$. Five superimposed representative traces are shown for each allele. $B$, Average EJC amplitudes are shown for basal stimulation $(1 \mathrm{~Hz})$ up to high-frequency stimulation $(20 \mathrm{~Hz})$, followed by repeat basal stimulation. All mutant EJC amplitudes are significantly decreased from that of wild type at all stimulation frequencies. The average area of the current responses was also analyzed, and similar significant decreases in mutant transmission were found (data not shown). Mean EJC amplitudes in each animal were determined from 25 consecutive EJCs evoked at each frequency. Average amplitudes were determined for at least six animals per strain. $C$, All stoned mutants exhibit a significant delay in evoked transmission. The duration from stimulation to the EJC peak is increased in all mutants, representative of delayed transmitter release (Mann-Whitney $U$ test, $\left.{ }^{* *} p<0.005 ;{ }^{* * *} p<0.001\right)$. $D$, Normalized cumulative current amplitude distributions for all stoned mutants are significantly delayed. The time to $I_{50}$ for all mutants is significantly delayed $(C, p<$ $0.0001 ; 13-120, p=0.038 ; R 9-10, p=0.042 ;$ PH1,$p=$ $0.0004)$. $E$, Control transmission responses to stimulation usually result in a single synchronous release of transmitter, whereas asynchronous release resulting from delayed vesicle fusion is frequently observed in all stoned mutants. The asynchronous release of transmitter was quantified by analysis of the number of $100+$ pA peaks per stimulus $\left({ }^{*} p<0.05 ;{ }^{* *} p<0.005\right.$; $* * * p<0.0001)$. $F$, EJC amplitudes vary greatly in stoned mutants. The poor fidelity of mutant transmission is displayed as high variability at different stimulation frequencies. $G$, Mutant NMJs show a significant transmission failure rate, whereas control synapses never fail. Failure rate is quantified in a stimulation series of $1-20 \mathrm{~Hz}$, followed by repeat stimulation at 1 Hz. $H$, The calcium dependence of transmission was determined for all the stoned mutants. The calcium cooperativity of release was similar for all stoned alleles and is not significantly different from the control as measured by the power relationship of the slope for wild type $(2.15)$ and for the mutants $(C=1.87 ; 13$ $120=1.66 ; R 9-10=1.54 ; P H 1=1.70)$. Each value represents the mean \pm SEM.
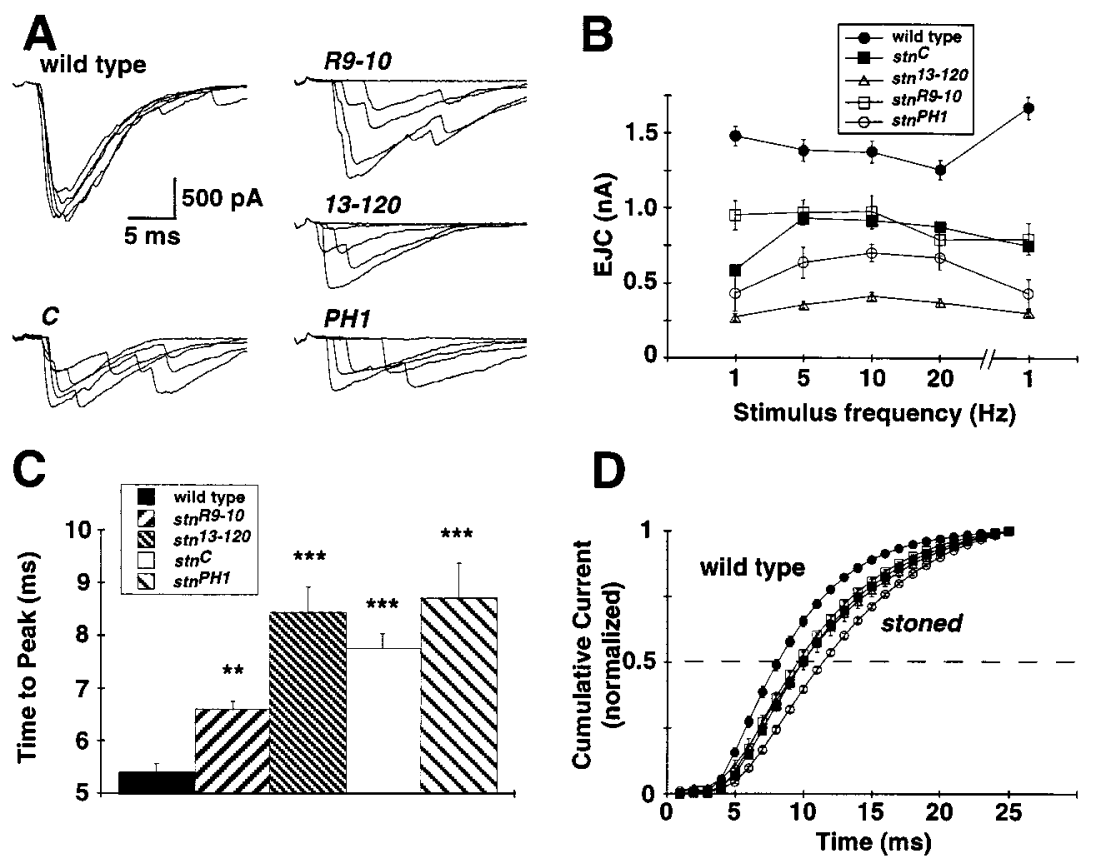

E

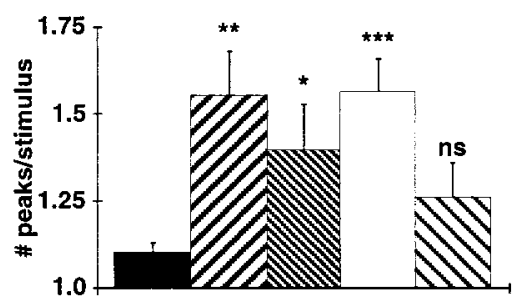

$\mathbf{F}$
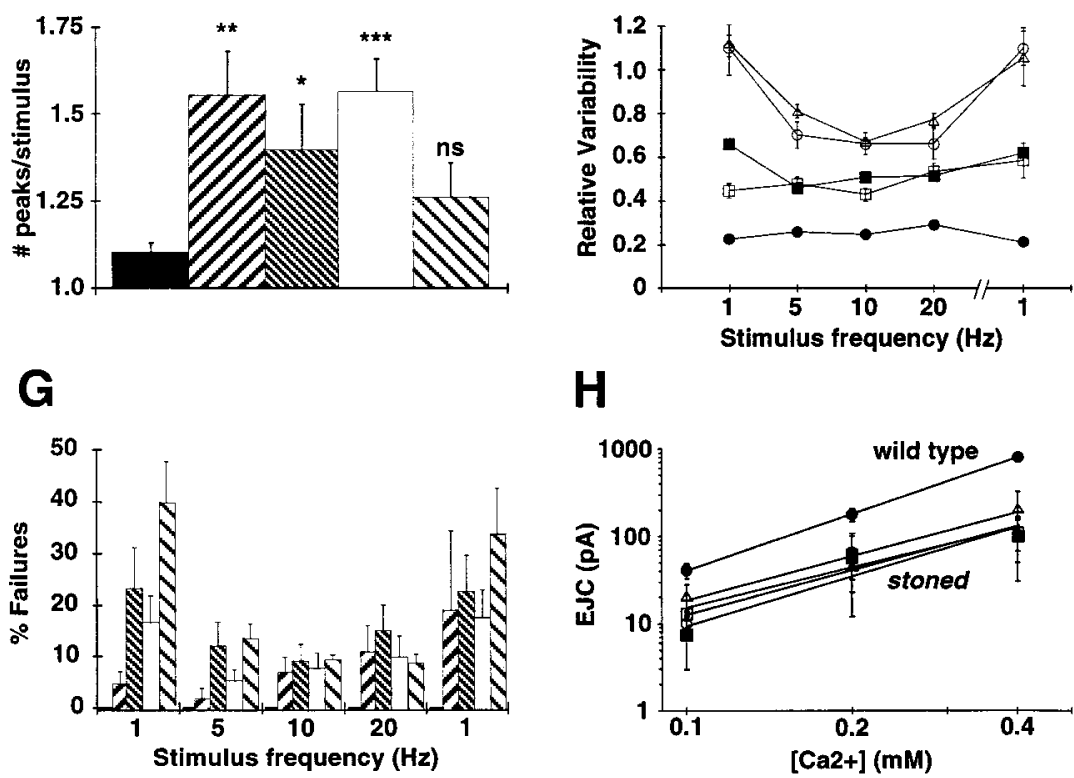

H

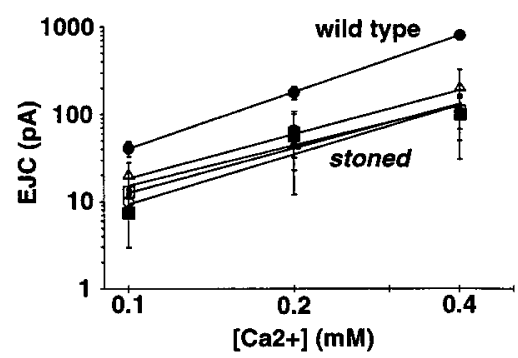

Johansen et al., 1989; Jia et al., 1993; Broadie et al., 1995). The pre- and postsynaptic membranes surrounding the t-bars are densely staining and are separated by a cleft $\sim 15 \mathrm{~nm}$ wide. Clear SVs of 30-40 nm diameter are observed to be clustered around the t-bars in a semicircular area with a radius of $\sim 250 \mathrm{~nm}$ (Fig. 8; see Materials and Methods for a discussion of radial dimension determination). Synaptic vesicles dock with the membrane immediately adjacent to t-bars in preparation for evoked fusion. For analytical purposes, vesicles are considered docked if distributed less than one vesicle diameter $(<30 \mathrm{~nm})$ from the plasma membrane at active sites (Heuser et al., 1979; Bommert et al., 1993; Hess et al., 1993; Hunt et al., 1994). Synaptic vesicles also appear outside the clusters surrounding t-bars, although at a much lower density than that of the clustered vesicles (Fig. 8; Table 1). Other membrane structures, such as large dense core vesicles and trans- lucent vesicles larger than typical SVs (presumed to be endosomes), are also occasionally observed in sections through boutons containing t-bars (Atwood et al., 1993; Jia et al., 1993).

Striking differences in synaptic ultrastructure are observed for all of the stoned mutant alleles relative to wild-type controls. Presynaptic boutons containing t-bars are present in all stoned alleles, and the association of presynaptic tissue with muscle cells is similar to that in wild type (Fig. 8), indicating that development of NMJs in the mutant embryos occurs normally. However, a striking reduction in the number and density of SVs present in boutons is observed in stoned mutants. All four stoned alleles have $\sim 50 \%$ fewer SVs clustered around the active zone t-bars (Table 1; Fig. 8), and SV density outside of the clustered radius surrounding t-bars is also reduced by $\sim 50 \%$ (Table 1 ). Analysis of $s_{n}{ }^{\mathrm{PH} 1} / \mathrm{Df}(1) \mathrm{HM} 430$ animals displayed features identical to that 

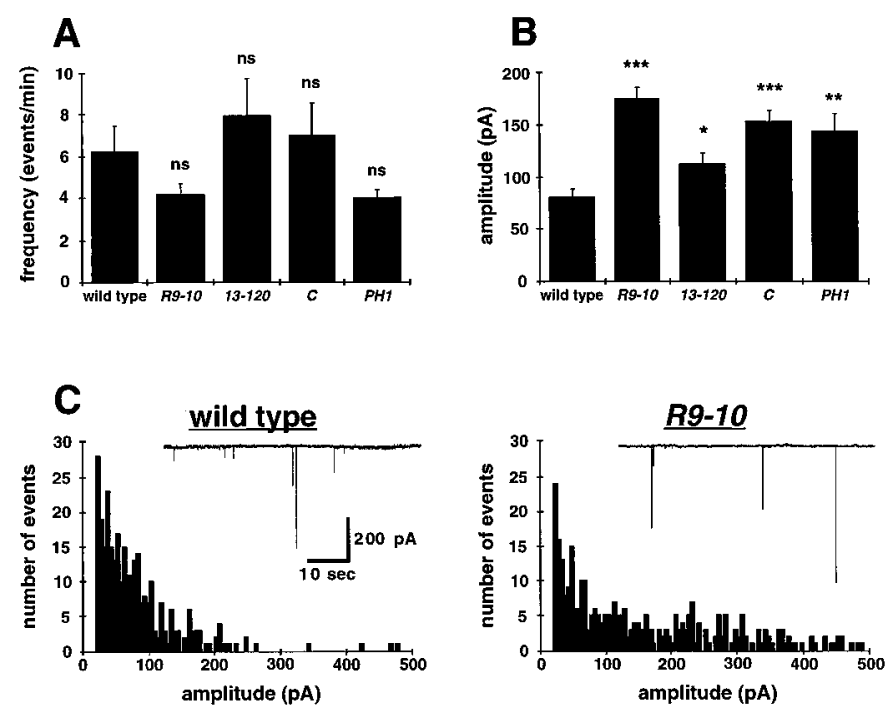

Figure 6. Miniature EJC amplitudes are increased in all stoned mutants. $A$, Spontaneous EJC events were collected at $0.5 \mathrm{mM} \mathrm{Ca}^{2+}$ in the presence of $0.1 \mu \mathrm{M}$ TTX. The frequency of events in all stoned alleles is not significantly ( $n s)$ different from that of wild-type embryos. $B$, The average type I MEJC amplitude is significantly increased for all stoned mutants $\left({ }^{*} p<0.05{ }^{* *} p<0.005 ;{ }^{* * *} p<0.0005\right)$. $C$, Current amplitude distributions of type I MEJCs in wild-type and $s t^{\mathrm{R} 9-10}$ embryos in 0.5 $\mathrm{mM} \mathrm{Ca}^{2+}$ are shown. The smallest quantal size event distribution is similar for both wild-type and mutant embryos; however, all stoned mutants display a significant increase in the number of abnormally large events $(>200 \mathrm{pA})$. Current amplitudes are divided into $5 \mathrm{pA}$ bins.

of animals hemizygous for $\operatorname{stn}^{\text {PH1 }}$ [clustered vesicles, $8.3 \pm 2.9$ ( $n=16$ synapses) and $8.4 \pm 0.6$ ( $n=8$ synapses), respectively]. A similar $50 \%$ reduction in the number of docked vesicles per t-bar was observed at $\operatorname{stn}^{13-120}$, $\sin ^{\mathrm{R} 9-10}$, and $\operatorname{stn}^{\mathrm{PH} 1}$ synapses, whereas the viable $\operatorname{stn}^{\mathrm{C}}$ allele has $\sim 30 \%$ fewer docked vesicles per t-bar than does wild type (Table 1). Thus, SV density is severely reduced in all mutant alleles, throughout the presynaptic bouton, at active zones, and in the number of docked vesicles.

An additional difference observed in stoned bouton ultrastructure was an increase in intermediates of the SV cycle (Table 1). In wild-type embryos, SVs are the most prominent membrane structures in sections through boutons containing t-bars (Fig. 8A) (Atwood et al., 1993). A much smaller number of translucent vesicles noticeably larger than SVs [cisternae (Jia et al., 1993) and early endosomes (Kadota et al., 1994)] are also present in these sections, and, rarely, multivesicular bodies (MVBs) are seen. The early endosomes represent a step in the normal synthetic pathway for SVs in these terminals. Increased numbers of MVBs have been reported previously as resulting from increased synaptic activity (Kadota and Kadota, 1982; Jia et al., 1993; Kadota et al., 1994). These MVBs are usually removed from the region of the active zone and are targeted to somatic lysosomes (Kadota et al., 1994). Because MVBs have been shown to contain SV proteins (Marxen et al., 1997), they represent the normal degradative route for synaptic proteins.

In stoned mutants, sections through boutons containing t-bars had a significantly greater number of large vesicles $(>60 \mathrm{~nm}$; endosomes and cisternae) than did wild-type synapses (Fig. 8; Table 1); $\operatorname{stn}^{\mathrm{C}}$ embryos had $\sim 60 \%$ more, $\operatorname{stn}^{13-120}$ and $\operatorname{stn}^{\mathrm{R} 9-10}$ embryos had an approximate twofold increase, and $s{ }^{\mathrm{PH} 1} \mathrm{em}-$ bryos had $>3.5$ times the number of large vesicles. In addition, a greater number of these large vesicles appeared within the SV cluster surrounding active zones in mutant embryos. The number of large vesicles present within the clustered radius of t-bars was at least three times greater in all of the mutant strains than in wild type (Table 1). Furthermore, a significant increase in the number of MVBs was observed in sections through boutons containing t-bars in stoned mutants (Fig. 8; Table 1). $\operatorname{stn}^{\mathrm{PH} 1}$ and $\operatorname{stn}^{\mathrm{C}}$ had an approximate fourfold increase in the number of MVBs compared with that in wild type. $\operatorname{stn}^{\mathrm{R} 9-10}$ had $\sim 3.5$ times more MVBs in sections containing t-bars than did wild-type embryos. Interestingly, no difference in the number of multivesicular bodies was observed between wild-type and $\operatorname{stn}^{13-120}$ embryos (Table 1).

These results indicate that the stoned mutants have normal gross synaptic morphology; however, these mutants display a severe reduction in synaptic vesicle number and an increase in recycling intermediates including large cisternae and MVBs. This ultrastructural analysis combined with the abnormal labeling of synaptotagmin and debilitated synaptic transmission strongly suggests a role for the stoned proteins in regulating the synaptic vesicle-recycling pathways.

\section{DISCUSSION}

\section{The stoned proteins are required for presynaptic function}

The dicistronic stoned locus produces two stoned proteins, STNA and STNB. Dicistronic loci are extremely rare in eukaryotic systems, although common in prokaryotes. By analogy with bacterial operons, it is probable that the two stoned proteins interact in the same biochemical pathway, which may require strict stoichiometric regulation. In support of this hypothesis, both stoned proteins are specifically expressed at synaptic terminals at central and peripheral synapses where they colocalize to the presynaptic

\begin{tabular}{|c|c|c|c|c|c|c|}
\hline Strain & $\begin{array}{l}\text { Clustered } \\
\text { vesicles }^{a}\end{array}$ & $\begin{array}{l}\text { Docked } \\
\text { vesicles }\end{array}$ & $\begin{array}{l}\text { Total SVs } \\
\left(\text { per } \mu \mathrm{m}^{2}\right)\end{array}$ & $\begin{array}{l}\text { Cisternae } \\
(>60 \mathrm{~nm})\end{array}$ & $\begin{array}{l}\text { Clustered } \\
\text { cisternae }\end{array}$ & MVBs \\
\hline WT & $21.27 \pm 0.95$ & $1.15 \pm 0.13$ & $73 \pm 5.7$ & $2.12 \pm 0.58$ & $0.40 \pm 0.21$ & $0.16 \pm 0.07$ \\
\hline $\operatorname{stn}^{13-120}$ & $7.78 \pm 0.61^{b}$ & $0.56 \pm 0.10^{c}$ & $35 \pm 5.3^{c}$ & $4.63 \pm 0.48^{c}$ & $2.15 \pm 0.35^{c}$ & $0.19 \pm 0.08^{e}$ \\
\hline$s t^{\mathrm{R} 9-10}$ & $9.89 \pm 0.60^{b}$ & $0.50 \pm 0.10^{c}$ & $30 \pm 2.8^{c}$ & $7.37 \pm 0.77^{b}$ & $2.39 \pm 0.33^{c}$ & $0.57 \pm 0.15^{d}$ \\
\hline$s t n^{\mathrm{PH} 1}$ & $8.36 \pm 0.57^{b}$ & $0.60 \pm 0.10^{c}$ & $30 \pm 2.7^{c}$ & $4.92 \pm 0.61^{c}$ & $2.26 \pm 0.35^{c}$ & $0.79 \pm 0.16^{c}$ \\
\hline$s t n^{\mathrm{C}}$ & $10.36 \pm 0.78^{b}$ & $0.80 \pm 0.14^{d}$ & $34 \pm 3.5^{c}$ & $3.38 \pm 0.43^{d}$ & $1.46 \pm 0.22^{c}$ & $0.92 \pm 0.19^{b}$ \\
\hline
\end{tabular}

\footnotetext{
${ }^{a}$ See Materials and Methods for description of methods and data parameters.

${ }^{b}$ Mann-Whitney $U$ test significance value related to wild type; $p<0.0005$; extremely significant.

${ }^{c} p<0.005$; very significant.

${ }^{d} p<0.05 ;$ significant.

${ }^{e} p>0.05$; not significant.
} 
A
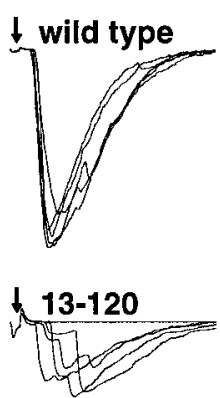

0 min
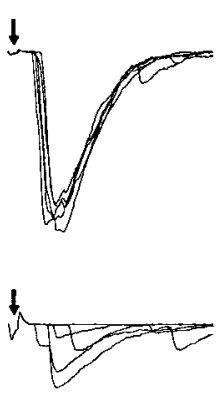

$2 \min$

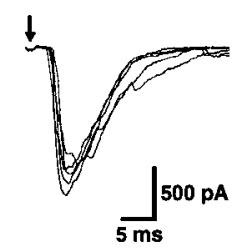

$\downarrow$

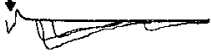

$5 \mathrm{~min}$
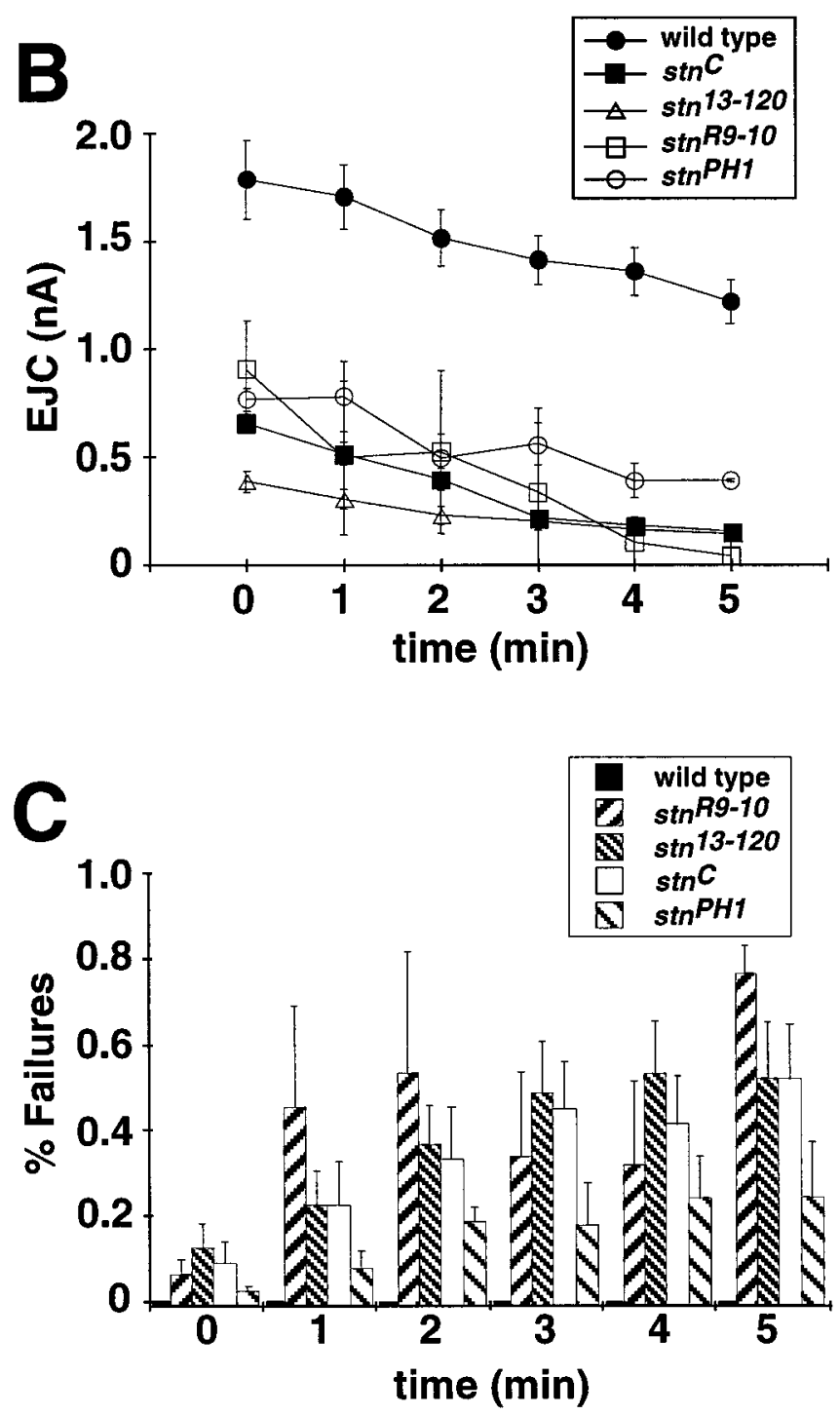

Figure 7. The stoned mutant synapses fatigue during prolonged stimulation. $A$, The NMJ was stimulated at $10 \mathrm{~Hz}$ in normal calcium $(1.8 \mathrm{~mm})$ over a 5 min period, and EJC amplitude was quantified throughout the protocol. Sample traces are shown for $t=0,2$, and $5 \mathrm{~min}$. Transmission becomes severely impaired in stoned mutants by the end of the stimulus protocol, and wild-type transmission remains relatively robust. $B$, Wildtype EJC amplitude decreases slightly $(\sim 25 \%)$ over the 5 min stimulus protocol, whereas stoned mutants display a relatively severe decrease $(50+\%)$ in transmission amplitude. EJC amplitudes at each time point are compartment. All four stoned mutants we analyzed show no detectable STNB expression in the synaptic terminal. The $\operatorname{stn}^{\mathrm{C}}$, $s^{\mathrm{R}}{ }^{\mathrm{R} 9-10}$, and $\operatorname{stn}^{13-120}$ mutant alleles also show a loss of STNA expression, whereas the $s t n^{\text {PH1 }}$ allele shows only moderately reduced STNA levels. Thus, the $\sin ^{\mathrm{PH} 1}$ allele appears to predominantly disrupt STNB, whereas the three other alleles disrupt both STNA and STNB. This effect on expression pattern is consistent with the genomic aberrations for the characterized alleles. Because of the polar nature of our mutations, we do not have the ability to assay STNA and STNB function independently at this time. Nevertheless, on the basis of the similar expression from a dicistronic locus, we suggest that STNA and STNB likely interact in the same or closely related pathways to enable presynaptic neurotransmission.

The stoned physiological phenotype includes decreased, asynchronous SV fusion in response to presynaptic stimulation. $\mathrm{Mu}-$ tant release is extremely variable and often consists of complete transmission failure. The viable allele $\operatorname{stn}^{\mathrm{C}}$ displays the least impaired neurotransmission of all our stoned mutants, consistent with the fact that the three other alleles are all embryonic lethal. This impaired, erratic transmission and, in particular, the asynchronous, delayed fusion of vesicles at stoned synapses are reminiscent of similar defects in the previously characterized null synaptotagmin mutants, although stoned mutant transmission remains considerably stronger than that in synaptotagmin mutants (Broadie et al., 1994). The similarity of phenotype may be caused, in part, by the specific mislocalization of Syt observed in all four stoned mutant alleles. Similar physiological results were seen for the $\sin ^{\mathrm{C}}$ viable allele in mature larval recordings, also shown to mislocalize Syt in the mature terminal (Stimson et al., 1998). In support of these results, biochemical studies have shown that both STNA and STNB bind to the C2B domain of Syt, STNB through its region of homology with AP50 and STNA through its N terminal 250 residues (L. Kelly, personal communication) (Stimson et al., 1998). Therefore, we propose that the stoned proteins have a specific role in the localization of Syt in the synaptic terminal through direct protein-protein interactions. It is likely that some of the synaptic defects reported in stoned mutants result from the loss of Syt in presynaptic boutons.

Nevertheless, it seems that the stoned proteins also play a central role in SV recycling that is independent of their role in Syt localization. Ultrastructural analyses of stoned synapses reveal an overall decrease in vesicle number, and prolonged stimulation of stoned synapses results in severe synaptic fatigue involving a dramatic increase in the frequency of synaptic failures. Null synaptotagmin mutants show a similar decrease in SV density, suggesting that Syt may also have a central role in endocytosis (Jorgensen et al., 1995; Reist et al., 1998). However, the stoned ultrastructural phenotype is as severe, or more severe, than that observed in syt null mutants, although stoned alleles result in only an $\sim 50 \%$ reduction of Syt in the synaptic terminal. Moreover, stoned mutants accumulate enlarged cisternae and MVBs, not observed in syt alleles (Jorgensen et al., 1995; Reist et al., 1998). These differences strongly suggest that the stoned proteins have a distinct functional role in the SV-recycling pathway independent of their function in Syt localization.

$\leftarrow$

averaged from 25 consecutive stimuli. $C$, The decreased EJC amplitude in stoned alleles is accompanied by a significant increase in failure rate. In each plot, points represent the mean \pm SEM for at least four embryos per genotype. 

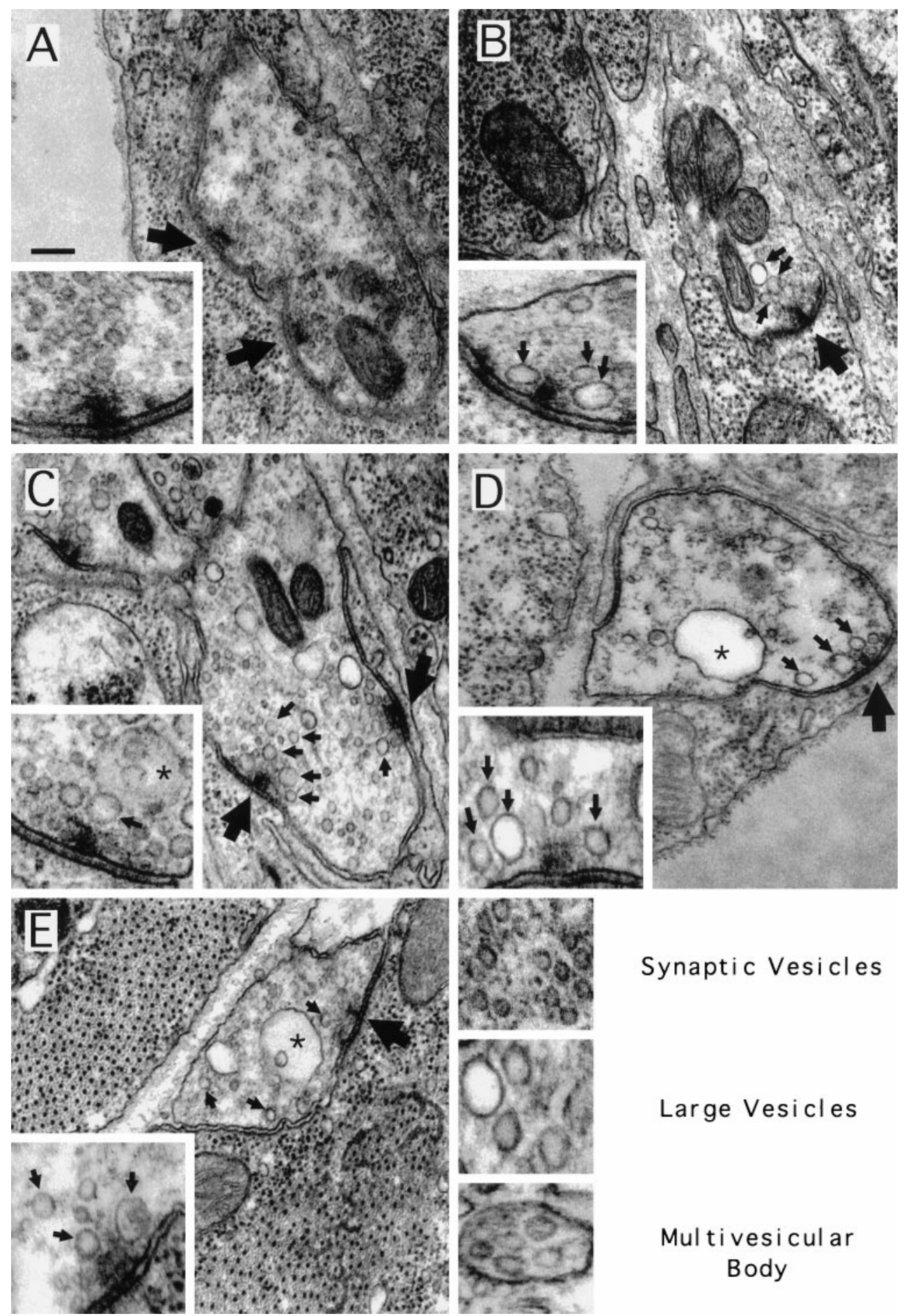

It should be noted that ultrastructural analysis of mature larval NMJs in the viable $\operatorname{stn}^{\mathrm{C}}$ mutant failed to identify any decrease in SV density, and indeed, a small increase in vesicle density was observed (Stimson et al., 1998). Differences between the embryonic and larval NMJs of $\operatorname{stn}^{\mathrm{C}}$ may be attributable to a postembryonic compensation mechanism in this viable, hypomorphic allele. Such compensation may simply be attributable to a masking effect because of the dramatic increase in vesicle density that arises during postembryonic development. Moreover, although no ultrastructural alterations in $\operatorname{stn}^{\mathrm{C}}$ were reported in the study by Stimson et al. (1998), we note that a marked increase in the

\section{Synaptic Vesicles}

Large Vesicles

\section{Mul tivesicular Body}

Figure 8. All stoned mutant alleles display a reduction of synaptic vesicles and accumulation of other membrane structures. Images of typical boutons (background) and active zones (insets) for wild-type $(A), \operatorname{stn}^{13-120}(B), \operatorname{stn}^{\text {R9-10 }}$ $(C), \operatorname{stn}^{\mathrm{PH} 1}(D)$, and $\operatorname{stn}^{\mathrm{C}}(E)$ mutants. Regular synaptic vesicles comprise the most prominent membrane structure in the wild-type bouton, and clusters of these vesicles are observed clustered around active zone t-bars (large arrows). In the mutant embryos, fewer synaptic vesicles are clustered around t-bars, and an increase in large, translucent vesicles (small arrows) was observed both in boutons and in regions proximal to t-bars. In some strains, an increase in multivesicular bodies (asterisks) was observed in boutons. Scale bar, $200 \mathrm{~nm}$.

number of enlarged cisternae structures appears present in their representative $\operatorname{stn}^{\mathrm{C}}$ electron micrograph [Stimson et al. (1998), their Fig. 5C], consistent with the observations reported here.

\section{Proper synaptic vesicle membrane recycling requires the stoned proteins}

Early models of synaptic membrane recycling suggested that newly endocytosed vesicles join a sorting endosome compartment before subsequent budding and maturation (Heuser and Reese, 1973) (Fig. 9A, arrow 1). In addition, under periods of sustained or high-frequency transmission, large patches of membrane may 


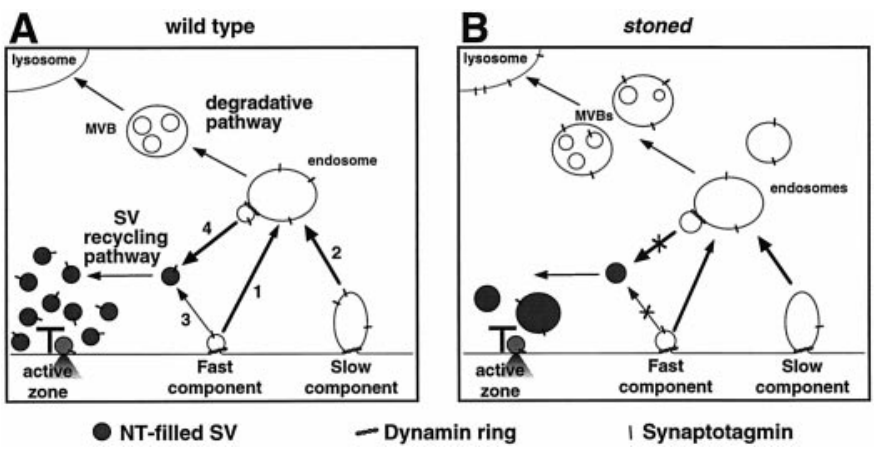

Figure 9. Schematic model of putative synaptic vesicle-recycling mechanisms at the presynaptic terminal. Synaptic vesicles release their contents by fusing with the plasma membrane at the active zone and are retrieved by a dynamin-mediated process that may recycle single vesicles under light stimulation (fast component) and may mediate bulk membrane retrieval under high-stimulus conditions (slow component). $A$, Numerous studies have suggested that synaptic vesicle-recycling mechanisms may require an endosomal-sorting step (arrows 1,2), although there is also evidence of a more direct mechanism (arrow 3). The hypothesized role of a sorting endosome is to retain functional synaptic vesicle proteins for the generation of new mature vesicles and to send old proteins to the somatic lysosomes for degradation via MVBs. $B$, Impaired vesicle recycling in stoned mutants results in a decrease of synaptic vesicles and an increase in recycling intermediates such as cisternae/endosomes and MVBs. Such data strongly suggest a role for stoned in the recycling of synaptic vesicles. The stoned mutants also display mislocalization and reduced levels of Syt, possibly because of loss of Syt to somatic lysosomes.

be retrieved from the plasma membrane to form an early endosome from which new vesicles may be generated (Kadota and Kadota, 1982; Koenig and Ikeda, 1989, 1996; Kadota et al., 1994; Artalejo et al., 1995; Takei et al., 1996) (Fig. 9A, arrow 2). Recent studies provide evidence that synapses may also recycle synaptic vesicle membrane directly, without first fusing with an endosomal-sorting compartment (Murthy and Stevens, 1998; Palfrey and Artalejo, 1998) (Fig. 9A, arrow 3). Evidence from Drosophila argues that these two recycling pathways may act in parallel, corresponding to functionally and spatially distinct vesicle pools (Koenig and Ikeda, 1996; Kuromi and Kidokoro, 1998) (Fig. 9A).

The stoned mutants are clearly defective in one or more of these recycling pathways. All alleles show a significant decrease in SVs at active zones and throughout the presynaptic terminal and a correspondingly increased sequestering of membrane in enlarged membranous compartments. These defects may result from a direct defect in endocytosis leading to improper regulation of vesicle size (Fig. 9, arrows 1, 4), or alternatively, the large vesicles may be endosomal compartments that accumulate owing to an inability to bud and segregate new SVs during endosomemediated recycling (Fig. 9, arrow 4). The existence of a population of very large-amplitude spontaneous fusion events $(200-500$ $\mathrm{pA}$ ) at stoned synapses suggests that these large vesicles can function to release neurotransmitter in a constitutive manner (similar to large dense-core vesicles). However, the apparent functional competence of these vesicles does not allow us to determine whether they represent abnormally large SVs or endosomes that have spilled over into the active zone.

The accumulation of MVBs may be more informative. These structures clearly derive from endosomes and represent a normal degradative pathway in which SV proteins and membrane are targeted to somatic lysosomes (Kadota and Kadota, 1982; Parton et al., 1992; Kadota et al., 1994). In parallel with MVB accumu- lation, we have demonstrated that Syt levels at the terminal and throughout the embryo decrease by $\sim 50 \%$ in stoned mutants. We therefore suggest that the stoned proteins are specifically involved in the recruitment and localization of Syt during SV recycling and, in the absence of correct targeting, that Syt is degraded via a default degradative pathway involving MVBs (Fig. 9B).

\section{The stoned proteins link SV recycling and synaptotagmin recruitment}

Mature synaptic vesicles have a specific complement of proteins required for a variety of functions. Each protein must be selectively recruited to the maturing SV during endocytosis. The mislocalization of Syt in stoned synapses is not accompanied by a loss of other SV proteins (e.g., synaptobrevin and CSP), suggesting that the stoned proteins may be involved in the specific recycling of Syt from endocytosed membrane. We hypothesize that the stoned proteins normally function at a choice point segregating recycled Syt protein into maturing synaptic SVs and away from the MVB degradative pathway.

Such a role has been suggested previously for the AP3 complex (Dell'Angelica et al., 1997; Simpson et al., 1997), shown recently to be required for localization of an SV transporter protein (Wenzel et al., 1997; Kantheti et al., 1998) and to be required for the generation of SVs (Salem et al., 1998). Similarly, the Drosophila gene LAP, which encodes AP180 (associated with clathrindependent endocytosis with the AP2 complex), has been shown recently to be involved in regulating SV size and the proper recruitment of the vesicle coat protein clathrin (Zhang et al., 1998). In the $C$. elegans AP180 mutant (UNC-11), the protein also seems to have a specific role in recruiting synaptobrevin to the recycled vesicle (E. Jorgensen, personal communication). These AP180 data, combined with the observation that SV size is not altered in mutant animals lacking synaptobrevin (Broadie et al., 1995), suggest that AP180 has two distinct functions: structural budding of membrane and the specific recycling of synaptobrevin.

The similarities between these studies lead to the hypothesis that there may be separate mechanisms required for the recycling of each distinct SV protein and that these mechanisms may be intimately integrated into the membrane-budding machinery. Such a coupled mechanism would guarantee that newly generated $\mathrm{SVs}$ have the correct functional complement of SV proteins. Clearly, within this general mechanism, the stoned proteins couple the specific recruitment of Syt to proper SV biogenesis. The stoned proteins may participate in the AP2-mediated plasma membrane mechanism or, alternatively, act in a separate and/or later site such as AP3-mediated endosomal sorting to direct the recruitment and/or localization of Syt into mature SVs. Ongoing experiments are aimed at testing the site and/or mechanism of stoned function by determining the exact location of stoned function in the SV-recycling pathway.

\section{REFERENCES}

Andrews J, Smith M, Merakovsky J, Coulson M, Hannan F, Kelly LE (1996) The stoned locus of Drosophila melanogaster produces a dicistronic transcript and encodes two distinct polypeptides. Genetics 143:1699-1711.

Artalejo CR, Henley JR, McNiven MA, Palfrey HC (1995) Rapid endocytosis coupled to exocytosis in adrenal chromaffin cells involves $\mathrm{Ca} 2+, \mathrm{GTP}$, and dynamin but not clathrin. Proc Natl Acad Sci USA 92:8328-8332.

Atwood HL, Govind CK, Wu CF (1993) Differential ultrastructure of synaptic terminals on ventral longitudinal abdominal muscles in Drosophila larvae. J Neurobiol 24:1008-1024. 
Bennett MK, Scheller RH (1994) A molecular description of synaptic vesicle membrane trafficking. Annu Rev Biochem 63:63-100.

Betz WJ, Angleson JK (1998) The synaptic vesicle cycle. Annu Rev Physiol 60:347-363.

Bommert K, Charlton MP, DeBello WM, Chin GJ, Betz H, Augustine GJ (1993) Inhibition of neurotransmitter release by C2-domain peptides implicates synaptotagmin in exocytosis. Nature 363:163-165.

Broadie K (1994) Synaptogenesis in Drosophila: coupling genetics and electrophysiology. J Physiol (Paris) 88:123-139.

Broadie K (1998) Forward and reverse genetic approaches to synaptogenesis. Curr Opin Neurobiol 8:128-138.

Broadie K, Bellen HJ, DiAntonio A, Littleton JT, Schwarz TL (1994) Absence of synaptotagmin disrupts excitation-secretion coupling during synaptic transmission. Proc Natl Acad Sci USA 91:10727-10731.

Broadie K, Prokop A, Bellen HJ, O'Kane CJ, Schulze KL, Sweeney ST (1995) Syntaxin and synaptobrevin function downstream of vesicle docking in Drosophila. Neuron 15:663-673.

Broadie KS (1995) Genetic dissection of the molecular mechanisms of transmitter vesicle release during synaptic transmission. J Physiol (Paris) $89: 59-70$.

Broadie KS, Bate M (1993a) Development of the embryonic neuromuscular synapse of Drosophila melanogaster. J Neurosci 13:144-166.

Broadie KS, Bate M (1993b) Development of larval muscle properties in the embryonic myotubes of Drosophila melanogaster. J Neurosci 13:167-180.

Byers D, Davis RL, Kiger JA (1981) Defect in cyclic AMP phosphodiesterase due to the dunce mutation of learning in Drosophila melanogaster. Nature 289:79-81.

Ceccarelli B, Hurlbut WP, Mauro A (1973) Turnover of transmitter and synaptic vesicles at the frog neuromuscular junction. J Cell Biol $57: 499-524$.

Chen MS, Obar RA, Schroeder CC, Austin TW, Poodry CA, Wadsworth SC, Vallee RB (1991) Multiple forms of dynamin are encoded by shibire, a Drosophila gene involved in endocytosis. Nature 351:583-586.

Cremona O, De Camilli P (1997) Synaptic vesicle endocytosis. Curr Opin Neurobiol 7:323-330.

De Camilli P, Takei K (1996) Molecular mechanisms in synaptic vesicle endocytosis and recycling. Neuron 16:481-486.

De Camilli P, Takei K, McPherson PS (1995) The function of dynamin in endocytosis. Curr Opin Neurobiol 5:559-565.

Dell'Angelica EC, Ohno H, Ooi CE, Rabinovich E, Roche KW, Bonifacino JS (1997) AP-3: an adaptor-like protein complex with ubiquitous expression. EMBO J 16:917-928.

Dudai Y, Jan YN, Byers D, Quinn WG, Benzer S (1976) dunce, a mutant of Drosophila deficient in learning. Proc Natl Acad Sci USA 73:1684-1688.

Govind CK, De Rosa RA, Pearce J (1980) Presynaptic dense bars at neuromuscular synapses of the lobster, homarus americanus. Cell Tissue Res 207:81-88

Grigliatti TA, Hall L, Rosenbluth R, Suzuki DT (1973) Temperaturesensitive mutations in Drosophila melanogaster. XIV. A selection of immobile adults. Mol Gen Genet 120:107-114.

Harrison SD, Broadie K, van de Goor J, Rubin GM (1994) Mutations in the Drosophila Rop gene suggest a function in general secretion and synaptic transmission. Neuron 13:555-566.

Hess SD, Doroshenko PA, Augustine GJ (1993) A functional role for GTP-binding proteins in synaptic vesicle cycling. Science 259:1169-1172.

Heuser JE, Reese TS (1973) Evidence for recycling of synaptic vesicle membrane during transmitter release at the frog neuromuscular junction. J Cell Biol 57:315-344.

Heuser JE, Reese TS, Dennis MJ, Jan Y, Jan L, Evans L (1979) Synaptic vesicle exocytosis captured by quick freezing and correlated with quantal transmitter release. J Cell Biol 81:275-300.

Homyk Jr T, Pye Q (1989) Some mutations affecting neural or muscular tissues alter the physiological components of the electroretinogram in Drosophila. J Neurogenet 5:37-48.

Homyk Jr T, Sheppard DE (1977) Behavioral mutants of Drosophila melanogaster. Genetics 87:95-128.

Hunt JM, Bommert K, Charlton MP, Kistner A, Habermann E, Augustine GJ, Betz H (1994) A post-docking role for synaptobrevin in synaptic vesicle fusion. Neuron 12:1269-1279.

Jan LY, Jan YN (1982) Antibodies to horseradish peroxidase as specific neuronal markers in Drosophila and in grasshopper embryos. Proc Natl Acad Sci USA 79:2700-2704.
Jia XX, Gorczyca M, Budnik V (1993) Ultrastructure of neuromuscular junctions in Drosophila: comparison of wild type and mutants with increased excitability. J Neurobiol [Erratum (1994) 25:893-895] 24: $1025-1044$.

Johansen J, Halpern ME, Johansen KM, Keshishian H (1989) Stereotypic morphology of glutamatergic synapses on identified muscle cells of Drosophila larvae. J Neurosci 9:710-725.

Jorgensen EM, Hartwieg E, Schuske K, Nonet ML, Jin Y, Horvitz HR (1995) Defective recycling of synaptic vesicles in synaptotagmin mutants of Caenorhabditis elegans. Nature 378:196-199.

Kadota T, Kadota K (1982) Membrane retrieval by macropinocytosis in presynaptic terminals during transmitter release in cat sympathetic ganglia in situ. J Electron Microsc (Tokyo) 31:73-80.

Kadota T, Mizote M, Kadota K (1994) Dynamics of presynaptic endosomes produced during transmitter release. J Electron Microsc (Tokyo) 43:62-71.

Kantheti P, Qiao X, Diaz ME, Peden AA, Meyer GE, Carskadon SL, Kapfhamer D, Sufalko D, Robinson MS, Noebels JL, Burmeister M (1998) Mutation in AP-3 delta in the mocha mouse links endosomal transport to storage deficiency in platelets, melanosomes, and synaptic vesicles. Neuron 21:111-122.

Kelly LE (1983) An altered electroretinogram transient associated with an unusual jump response in a mutant of Drosophila. Cell Mol Neurobiol 3:143-149.

Koenig JH, Ikeda K (1989) Disappearance and reformation of synaptic vesicle membrane upon transmitter release observed under reversible blockage of membrane retrieval. J Neurosci 9:3844-3860.

Koenig JH, Ikeda K (1996) Synaptic vesicles have two distinct recycling pathways. J Cell Biol 135:797-808.

Koenig JH, Saito K, Ikeda K (1983) Reversible control of synaptic transmission in a single gene mutant of Drosophila melanogaster. J Cell Biol 96:1517-1522.

Kosaka T, Ikeda K (1983) Possible temperature-dependent blockage of synaptic vesicle recycling induced by a single gene mutation in Drosophila. J Neurobiol 14:207-225.

Kuromi H, Kidokoro Y (1998) Two distinct pools of synaptic vesicles in single presynaptic boutons in a temperature-sensitive Drosophila mutant, shibire. Neuron 20:917-925.

Lahey T, Gorczyca M, Jia XX, Budnik V (1994) The Drosophila tumor suppressor gene dlg is required for normal synaptic bouton structure. Neuron 13:823-835.

Littleton JT, Bellen HJ, Perin MS (1993) Expression of synaptotagmin in Drosophila reveals transport and localization of synaptic vesicles to the synapse. Development 118:1077-1088.

Marxen M, Maienschein V, Volknandt W, Zimmermann H (1997) Immunocytochemical localization of synaptic proteins at vesicular organelles in PC12 cells. Neurochem Res 22:941-950.

Murthy VN, Stevens CF (1998) Synaptic vesicles retain their identity through the endocytic cycle. Nature 392:497-501.

Osborne MP (1975) The ultrastructure of nerve muscle synapses. In: Insect muscle (Usherewood PNR, ed), pp 151-205: New York: Academic.

Palfrey HC, Artalejo CR (1998) Vesicle recycling revisited: rapid endocytosis may be the first step. Neuroscience 83:969-989.

Parton RG, Schrotz P, Bucci C, Gruenberg J (1992) Plasticity of early endosomes. J Cell Sci 103:335-348.

Petersen SA, Fetter RD, Noordermeer JN, Goodman CS, DiAntonio A (1997) Genetic analysis of glutamate receptors in Drosophila reveals a retrograde signal regulating presynaptic transmitter release. Neuron 19:1237-1248.

Petrovich TZ, Merakovsky J, Kelly LE (1993) A genetic analysis of the stoned locus and its interaction with dunce, shibire and Suppressor of stoned variants of Drosophila melanogaster. Genetics 133:955-965.

Probst JW, Ko CP (1987) Correlations between active zone ultrastructure and synaptic function studied with freeze-fracture of physiologically identified neuromuscular junctions. J Neurosci 7:3654-3664.

Prokop A, Landgraf M, Rushton E, Broadie K, Bate M (1996) Presynaptic development at the Drosophila neuromuscular junction: assembly and localization of presynaptic active zones. Neuron 17:617-626.

Reist NE, Buchanan J, Li J, DiAntonio A, Buxton EM, Schwarz TL (1998) Morphologically docked synaptic vesicles are reduced in synaptotagmin mutants of Drosophila. J Neurosci 18:7662-7673.

Roos J, Kelly RB (1998) Dap160, a neural-specific Eps15 homology and multiple SH3 domain-containing protein that interacts with Drosophila dynamin. J Biol Chem 273:19108-19119. 
Salcini AE, Confalonieri S, Doria M, Santolini E, Tassi E, Minenkova O, Cesareni G, Pelicci PG, Di Fiore PP (1997) Binding specificity and in vivo targets of the $\mathrm{EH}$ domain, a novel protein-protein interaction module. Genes Dev 11:2239-2249.

Salem N, Faundez V, Horng JT, Kelly RB (1998) A v-SNARE participates in synaptic vesicle formation mediated by the AP3 adaptor complex. Nat Neurosci 1:551-556.

Schulze KL, Broadie K, Perin MS, Bellen HS (1995) Genetic and electrophysiological studies of Drosophila syntaxin-1A demonstrate its role in nonneuronal secretion and neurotransmission. Cell 80:311-320.

Shone CC, Quinn CP, Wait R, Hallis B, Fooks SG, Hambleton P (1993) Proteolytic cleavage of synthetic fragments of vesicle-associated membrane protein, isoform-2 by botulinum type B neurotoxin. Eur J Biochem 217:965-971.

Simpson F, Peden AA, Christopoulou L, Robinson MS (1997) Characterization of the adaptor-related protein complex, AP-3. J Cell Biol 137:835-845.

Stimson DT, Estes PS, Smith M, Kelly LE, Ramaswami M (1998) A product of the Drosophila stoned locus regulates neurotransmitter release. J Neurosci 18:9638-9649.

Sudhof TC (1995) The synaptic vesicle cycle: a cascade of protein-protein interactions. Nature 375:645-653.

Sweeney ST, Broadie K, Keane J, Niemann H, O'Kane CJ (1995) Targeted expression of tetanus toxin light chain in Drosophila specifically eliminates synaptic transmission and causes behavioral defects. Neuron 14:341-351.

Takei K, Mundigl O, Daneill L, De Camilli P (1996) The synaptic vesicle cycle: a single vesicle budding step involving clathrin and dynamin. J Cell Biol 133:1237-1250.

Tebar F, Sorkina T, Sorkin A, Ericsson M, Kirchhausen T (1996) Eps15 is a component of clathrin-coated pits and vesicles and is located at the rim of coated pits. J Biol Chem 271:28727-28730.

Wenzel HJ, Cole TB, Born DE, Schwartzkroin PA, Palmiter RD (1997) Ultrastructural localization of zinc transporter-3 (ZnT-3) to synaptic vesicle membranes within mossy fiber boutons in the hippocampus of mouse and monkey. Proc Natl Acad Sci USA 94:12676-12681.

Wu MN, Bellen HJ (1997) Genetic dissection of synaptic transmission in Drosophila. Curr Opin Neurobiol 7:624-630.

Zhang B, Koh YH, Beckstead RB, Budnik V, Ganetzky B, Bellen HJ (1998) Synaptic vesicle size and number are regulated by a clathrin adaptor protein required for endocytosis. Neuron 21:1465-1475.

Zhang YQ, Broadie K (1999) Cloning, mapping and tissue-specific expression of Drosophila clathrin-associated protein AP50 gene. Gene, in press.

Zhong Y, Wu CF (1991) Altered synaptic plasticity in Drosophila memory mutants with a defective cyclic AMP cascade. Science 251:198-201.

Zusman S, Coulter D, Gergen JP (1985) Lethal mutations induced in the proximal X chromosome of Drosophila melanogaster using P-M hybrid dysgenesis. Drosophila Inform Serv 61:217-218. 